\title{
Psychotherapy for Substance Use Disorders - the importance of affects
}

\author{
My Frankl
}

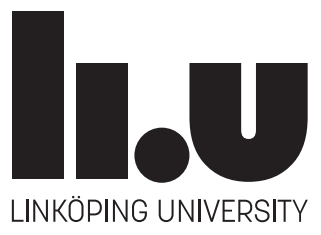

Linköping Studies in Arts and Science No. 726

Linköping Studies in Behavioural Science No. 202

Faculty of Arts and Sciences

Linköping 2017 
Linköping Studies in Arts and Science • No. 726

Linköping Studies in Behavioural Science No. 202

At the Faculty of Arts and Sciences at Linköping University, research and doctoral studies are carried out within broad problem areas. Research is organized in interdisciplinary research environments and doctoral studies mainly in graduate schools. Jointly, they publish the series Linköping Studies in arts and Science. This thesis comes from the department of Psychology at the Department of Behavioural Sciences and Learning.

Distributed by:

Department of Behavioural Sciences and Learning Linköping University

SE-581 83 Linköping

My Frankl

Psychotherapy for Substance Use Disorders - the importance of affects

Edition 1:1

ISBN 978-91-7685-429-7

ISSN 0282-9800

ISSN 1654-2029

(C) My Frankl

Department of Behavioural Sciences and Learning 2017

Cover illustration: Frittflytande by Storm Dunder

Printed by: LiU-tryck, Linköping 2017 
"People can't change the past, but they can change the way they react to the past, and build a better future."

Leigh McCullough

To Storm, Isolde, Nanna \& Idun 


\section{Abstract}

Substance use disorder (SUD) is a serious disorder with severe consequences for the individual, the family and for society. Comorbidity is common in the SUD population and the diversity of the disorder calls for a multiplicity of treatment options.

The overall aim of this thesis was to explore the role of affects in psychotherapy for SUD. Further aims were to investigate affect-focused therapeutic orientations, demonstrate the importance of common factors and evaluate a measure of affect phobia.

In Study I a naturalistic design was employed to examine how the discrepancy between patients' expectations and experience of psychotherapy related to alliance in 41 patients: 24 in individual therapy and 17 in group. An additional analysis concerned whether different dimensions of role expectations predicted retention in psychotherapy. Study II was the first psychometric evaluation of the Affect phobia test - a test developed to screen the ability to experience, express and regulate emotions. Data were collected from two samples: A clinical sample of 82 patients with depression and/or anxiety participating in a randomized controlled trial of Internet-based affectfocused treatment, and a university student sample of 197 students. Data analysed included internal consistency, test-retest reliability, factor analysis and calculation of an empirical cut-off. Study III focused on the feasibility of individual 10 week Affect Phobia Therapy (APT) for patients diagnosed with mild to moderate alcohol use disorder (AUD) and problematic affective avoidance in a nonconcurrent multiple baseline design. Study IV comprised an evaluation of the feasibility and preliminary effectiveness of APT adapted to a structured group format for patients $(\mathrm{n}=22)$ with comorbid substance use disorder and ADHD with core features of affective avoidance/emotion dysregulation in an open design.

In Study $I$ an overall discrepancy between role expectations and experiences was significantly related to a lower level of therapeutic alliance in group therapy. This relationship was not found in individual therapy. Expectations prior to psychotherapy characterized by defensiveness correlated negatively with therapy retention, even when controlling for waiting time for therapy. In Study II the internal consistency for the total score on the Affect phobia test was satisfactory but it was not for the affective domains, Anger/Assertion, Sadness/Grief, and Attachment/Closeness. Test retest reliability was satisfactory. The exploratory factor analysis resulted in a six-factor solution and only moderately matched the test's original affective domains. An empirical cutoff between the clinical and the university student sample were calculated 
and yielded a cut-off of 72 points. In Study III patients reported no adverse events due to the treatment and finished the whole study period. The patients had different trajectories of alcohol consumption and craving and the hypothesis that heavy episodic drinking would subside during the time in therapy did not hold true. In Study IV patients reported significant pre-to post changes in increased self-compassion and decreased affect phobia but no change in psychological distress or emotion dysregulation. Craving fluctuated throughout the study period and patients' drinking pattern changed in the direction of more social drinking.

Main conclusions are the following: The Affect Phobia Test is a useful screening instrument for detecting emotional difficulties related to psychological malfunction. APT in both group and individual format are feasible treatments for the SUD population and has the potential to broaden the treatment options for some patients with SUD. Investigating expectations and fears prior to therapy may be means to prevent attrition.

Key words: Substance Use Disorder; comorbidities; emotion; dynamic therapy; affect focused experiential therapy; self-compassion; ADHD; role expectations; working alliance. 


\section{Empirical studies}

The thesis is based on the following original research papers, which are referred to in the text by their roman numerals:

I. Frankl, M., Wennberg, P. \& Philips, B. (2014). Role expectations and experiences - Discrepancy and therapeutic alliance among patients with substance use disorders. Psychology and Psychotherapy: Theory, Research and Practice, 87, 411-24. Doi: 10.1111/papt.1221

II. Frankl, M., Philips, B., Berggraf, L., Ulvenes, P., Johansson, R. \& Wennberg, P. (2016). Psychometric properties of the Affect Phobia Test. Scandinavian Journal of Psychology, 57, 482-488. Doi:10.1111/sjop.12308

III. Frankl, M., Wennberg, P., Berggraf, L. \& Philips, B. (2017) Affect Phobia Therapy for Alcohol Dependence - A multiple baseline study. Submitted and under revision for resubmission

IV. Frankl, M., Wennberg, P., Konstenius, M. \& Philips, B. (2017). Affect Phobia Group Therapy for comorbid Substance Use Disorder and ADHD. Submitted. 


\section{ABBREVIATIONS}

ACT

ADHD

AEDP

AUD

AUDIT

APT

Brown ADD-scale

CBT

CDT

$\mathrm{CM}$

DBT

DET

DSM-IV

DSM-5

DUDIT

HED

EFT

EK

ER

ERSQ

EU

GPT

ISTDP

MINI

MOPACS

NACC

OCD

OQ-45

OQ-10

HPA-axis

PACS

PEX

PEX-S

REED

SBU
Acceptance commitment therapy

Attention deficit hyperactivity disorder Accelerated experiential dynamic therapy Alcohol use disorder

Alcohol use disorder identification test

Affect Phobia Therapy

Brown attention deficit disorder scale

Cognitive behavior therapy

Carbohydrate deficient transferrin

Clinical management

Dialectic behaviour therapy

Differential emotion theory

Diagnostic and statistical manual of mental disorders, 4th edition

Diagnostic and statistical manual of mental disorders, 5th edition

Drug use disorder identification test

Heavy episodic drinking

Emotion focused therapy

Emotional knowledge

Emotional regulation

Emotion-regulation skills questionnaire

Emotional utilization

Cognitive behavior group treatment

Intensive short-term dynamic psychotherapy

Mini international psychiatric intervention

Matching and outcome of psychotherapy at

addiction clinics in Sweden

Nucleus accumbens

Obsessive compulsive disorder

Outcome questionnaire-45

Outcome questionnaire-10

Hypothalamic-pituitary adrenocortical axis

Penn alcohol craving scale

Psychotherapy expectations and experiences questionnaire

Psychotherapy expectations and experiences questionnaire-short

Role expectation and experiences discrepancy

Swedish Council on Health Technology 
SCS

SCID-I

SCID-II

SUD

STDP

TLFB

VAS-scale

VTA

WAI-S
Self compassion scale

Structured Clinical Interview for DSM-IV axis

I disorders

Structured Clinical Interview for DSM-IV axis

II disorders

Substance use disorder

Short-term dynamic therapy

Timeline follow back

Visual analogue scale

Ventral tegmental area

Working Alliance Inventory-short 


\section{Table of contents}

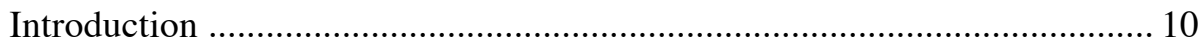

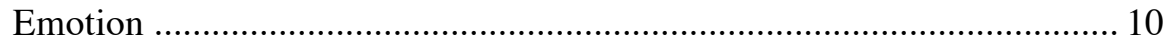

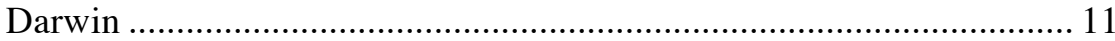

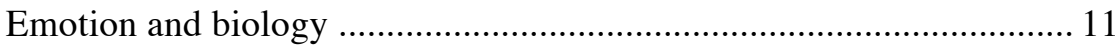

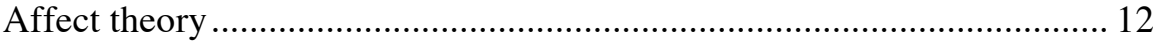

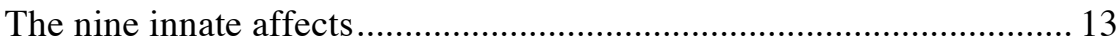

Affect, feeling and emotion ................................................................ 14

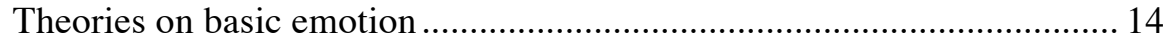

Emotion and cognition .................................................................... 15

Emotion and developmental psychology ............................................... 17

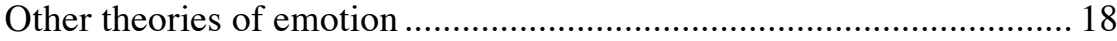

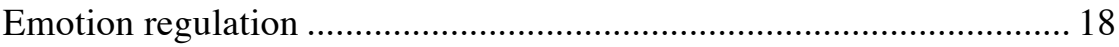

Phobia for affects/experiential avoidance.................................................. 19

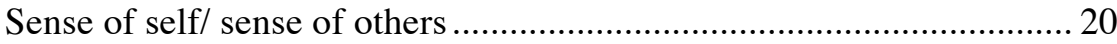

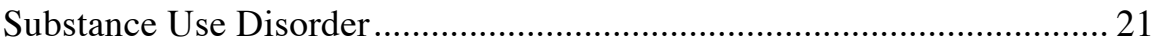

Classification of substance use disorder ................................................. 21

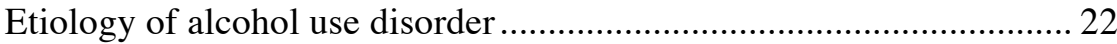

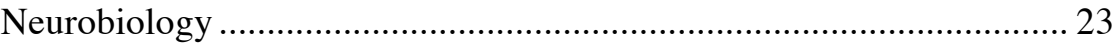

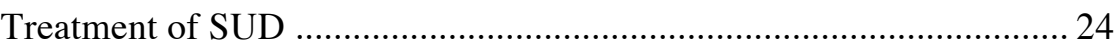

The role of emotion in substance use disorder ..................................... 24

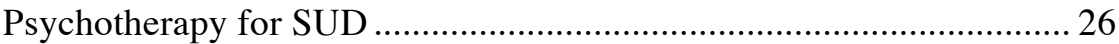

The role of emotion and sense of self in dynamic psychotherapy ............ 27

The role of emotion and cognition in dynamic psychotherapy ............. 28

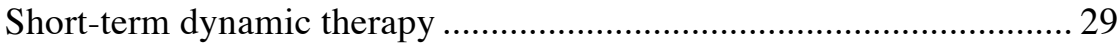

Affect phobia therapy …………........................................................... 29

Sense of self/self-compassion, sense of others/closeness ....................... 31

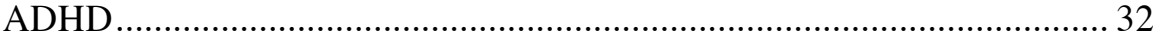




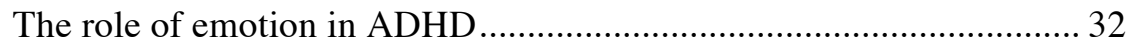

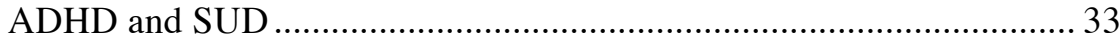

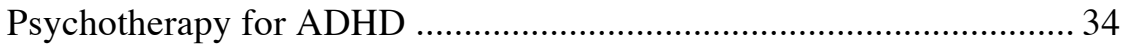

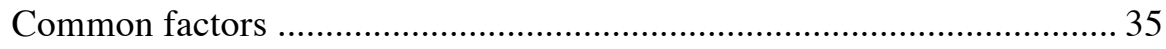

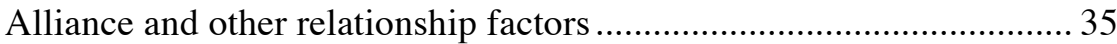

Role expectations and other client factors .............................................. 35

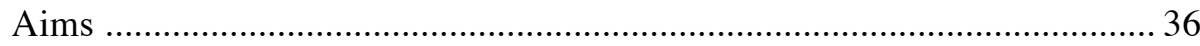

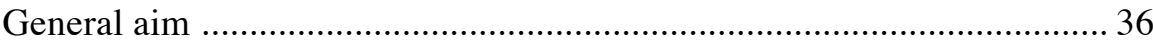

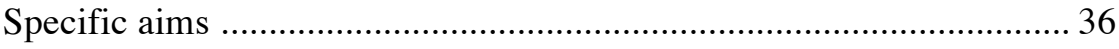

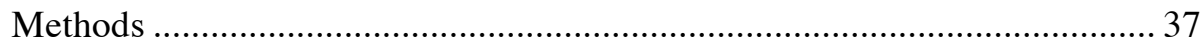

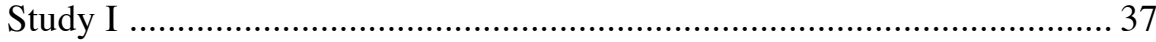

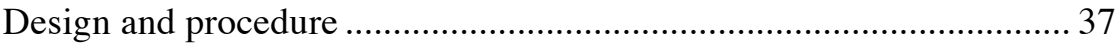

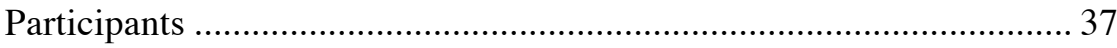

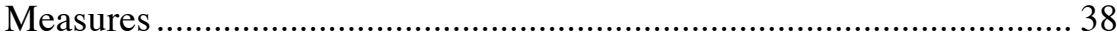

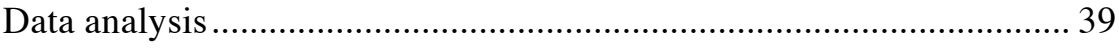

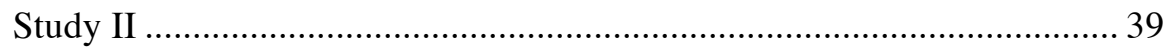

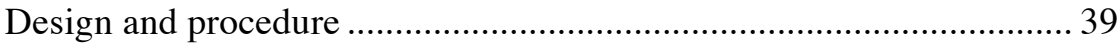

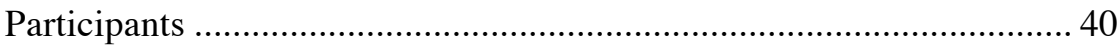

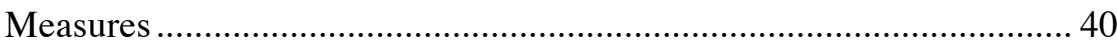

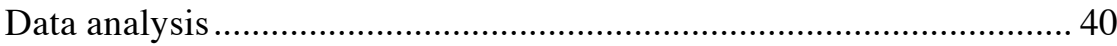

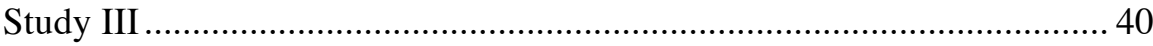

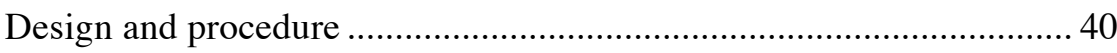

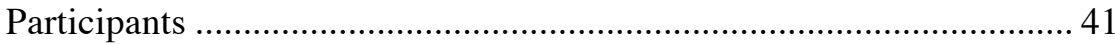

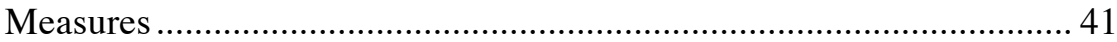

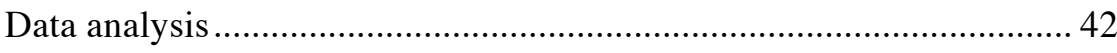

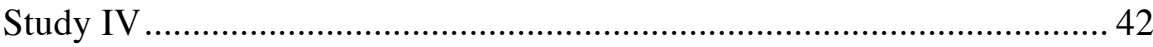

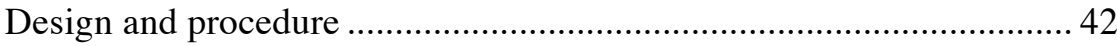

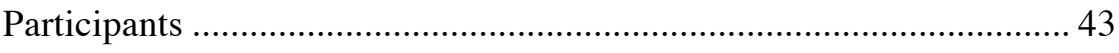

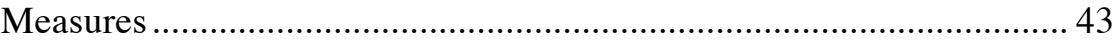

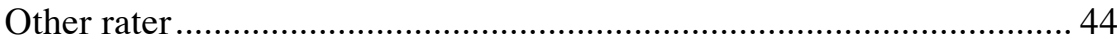




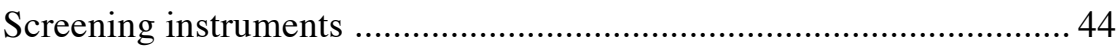

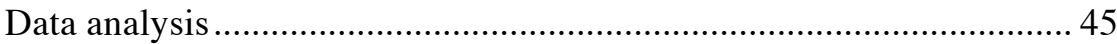

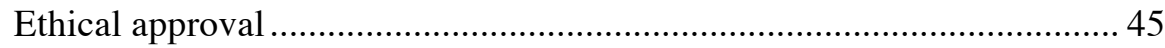

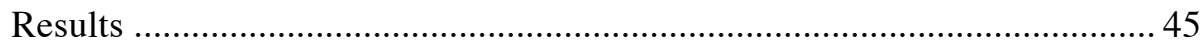

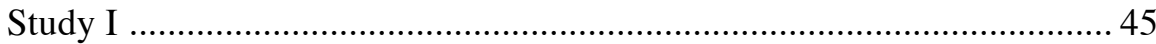

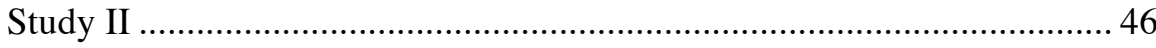

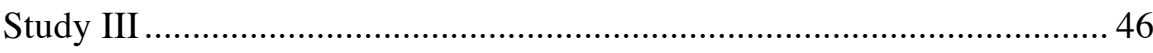

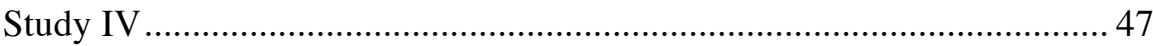

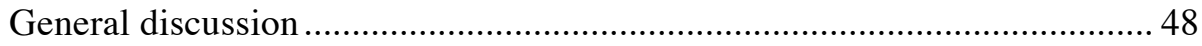

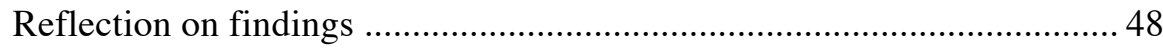

Affect phobia and its relation to psychiatric function ........................... 48

Affect phobia therapy for substance use disorder .................................. 49

The importance of self-compassion/positive feelings for self............... 53

Difficulties in measuring adaptive affective functioning ...................... 53

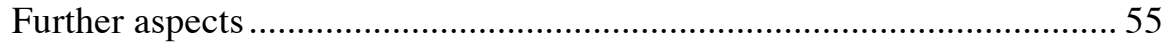

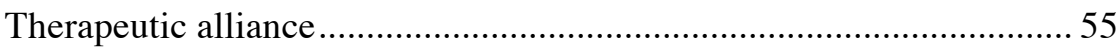

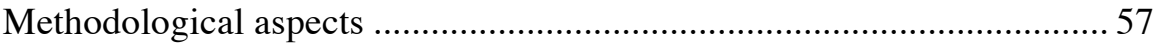

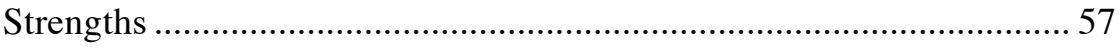

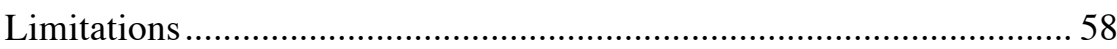

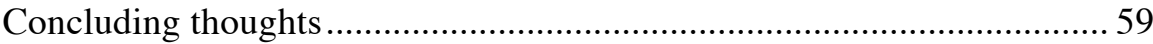

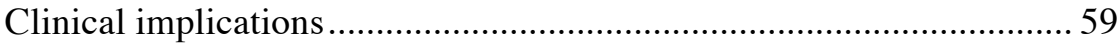

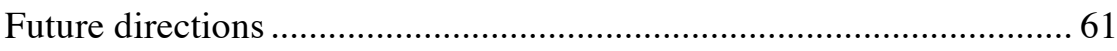

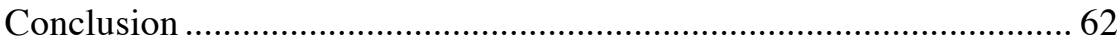

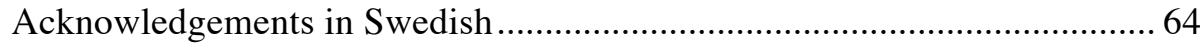

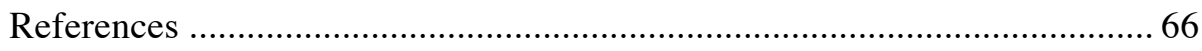




\section{Introduction}

Emotions have always been a central target in psychodynamic psychotherapy, since they play an important role in psychological well-being and illness (Freud, 1977; Greenberg \& Safran, 1987; Kohut, 1977). However, emotion focused interventions and their relation to outcomes have come into focus in recent decades of psychotherapy research (Greenberg, 2012). The effectiveness of psychotherapy has been demonstrated through years of outcome research (Lambert, 2013; Wampold \& Imel, 2013), and process research is now focusing on the question of why psychotherapy works and what in therapy constitute the mechanisms of change (Crits-Christoph, Johnson, Connolly Gibbons, \& Mukherjee, 2013). In a meta-analysis (Diener, Hilsenroth, \& Weinberger, 2007), the impact of eliciting affects in psychodynamic psychotherapy in relation to outcome was examined. The findings showed that therapist facilitation of patient affective expressions was an important element. In experiential psychotherapy the importance of emotional activation in session is essential and seen as a change mechanism. The emotional processing involves experiencing and tolerating emotions as well as integrating emotion and cognition (Greenberg, 1986).

\section{Emotion}

The terms emotion, affect and feeling are related but often indistinctly defined. In the literature affect and basic or discrete emotion refer to innate biological processes of emotion. In this thesis affect and emotion will be used interchangeably. The study of emotions is one of the fastest-growing areas in psychology and in neuroscience it has become clear that affects hold a central position in almost all phenomena that are characterized as mental processes (Cacioppo et al., 2007; Sweatt, 2013), since it constitutes an adaptive component in human function on par with cognition (LeDoux, 2012). Still, there is little consensus about what constitutes an emotion and how it differs from other aspects of the mind (LeDoux, 2012). New knowledge thus seems to expand understanding of the complexity of emotion and its meaning in human life. The interest in emotion, however, is far from new. Current neuroscientific findings of evolutionary gains and learning mechanisms linked to affect (Davis \& Panksepp, 2011; LeDoux, 2012; Panksepp, 2013) are in accordance with Darwin's work on emotion (Darwin, 1872) and with Affect theory (Tomkins, 2008). 


\section{Darwin}

In Darwin's quest to understand human behaviour and its place in nature, one of his foci was the expression of emotions in animals, including humans (Darwin, 1872). He gathered information over long periods of time and by numerous methods from his expeditions around the world, but also by observing his own children. Darwin's wish was to identify the main characteristic involuntary emotional expressions. He studied and outlined emotional expressions muscularly and skeletally, paying extra attention to how emotions were manifested facially, but also in the body. Thus, Darwin proposed that humans signalled their emotional state to others through nonverbal communication. He gathered observations and proposed a complex system by which different emotions induce movements in the body and proposed that inherent emotions excite the nervous system in reactions such as a shiver, sweating or a faster heartbeat. These in turn influence the body to perform responses that serve to obtain relief or gratification from the reaction, e.g., screaming (used by babies to command their caregivers' attention), fighting or fleeing when attacked, which then become habitually associated reactions to that emotion.

Darwin suggested that emotional expressions were both involuntary and linked to the nervous system and evolved in humans because they were advantageous in the evolution of humanity. Consequently, emotions were essential and a mere anticipation of an emotion, such as joy, could hence cause vivid bodily reactions and movements, which displayed the importance of emotions and their generalizability. Darwin also suggested a principle of antithesis in which contradictory emotions such as grief and joy induced directly opposing bodily reactions. The shift between divergent emotions could appear instantaneously, suggesting that emotions were innate and directly connected to the automatic nervous system.

\section{Emotion and biology}

The link between emotion and the automatic nervous system has been recognized for a long time but the precise relationship between them is an area of debate (Norman, Berntson, \& Cacioppo, 2014). Research has tried to answer the question of whether there are emotion specific autonomic patterns. In a meta-analysis, support was found for emotion-specific ANS activity (Kreibig, 2010). Fear, sadness and anger were associated with larger heart rate responses compared with disgust. Anger was connected with elevated diastolic blood pressure as compared to fear, and disgust was associated with a larger skin conductance response compared to happiness. Apart from these findings, studies on discrete patterns of emotion-specific ANS responses are scarce. Thus, no basic emotion seems to involve entirely 
unique somato-visceral activity. Methodological constraints affect emotion research since studies use different and restricted measures of physiological actions. Many physiological responses are regulated both by the sympathetic and the parasympathetic nervous systems, which can make differences in physiological responses more difficult to identify, since the two often work against each other in a activation/deactivation pattern (Norman et al., 2014).

\section{Affect theory}

Silvan Tomkins (Tomkins, 2008) was much influenced by Darwin when he developed his theories of human motivation, which he thought was emotionally based with biological and evolutionary origins. Like Darwin, Tomkins believed that stimulation of the central nervous system was crucial for triggering emotions and that emotions were vital for the survival and evolution of human life. The universality of emotional manifestations depicted in facial expressions and bodily reactions served as evidence for the innate emotional motivational system with the function of protecting us from threats to our survival. Since there were so many stimuli to attend to, this could potentially cause stimulus confusion. Tomkins' idea was that emotions helped humans pay attention to the most important stimuli. The individual could only attend to a limited amount of information, whether the stimuli were inside the body or in the outside world. Although the individual's focus could shift quickly, it was not possible to concentrate on more than one thing at a time. Hence, Tomkins believed that stimulus confusion created the need for an affect system that informed the individual what stimulus was the most important to focus on. Therefore, affect had to be triggered for the stimulus to enter our conscious awareness.

Darwin did not make a definite distinction between involuntary and habitual expressions of emotions or whether the expression was unconscious or conscious. Tomkins, on the other hand, postulated that no learning was necessary for the individual to feel the affect. Instead, the affective system was inherited and ready to use from the minute the baby was born. Thus, Tomkins' understanding was that conscious awareness of affect was only possible after it had been triggered. There was no time for conscious thought to elicit emotional responses since the reaction needed to occur instantaneously for the sake of survival. In addition, only one affect at a time could be activated since that was what our awareness enabled. The function of affect was to amplify the stimulus and thereby elicit conscious attention to it. Tomkins' explanation of the amplifying process in the brain was that when one of the sensory systems detected a stimulus with certain criteria, the information was transmitted to the face and then back to the brain. In the course of the transmission, the response to the stimulus was amplified. 
Hence, the affective system evolved to assist humans to pay attention to matters of utmost importance to their survival. Consequently, according to Tomkins, affect had a very central role in the brain and he argued that affect's motivational force was more central than the other important motivational systems - hunger, thirst and sexuality - since a stimulus that triggers an emotional response can momentarily override all the other drives.

Tomkins described what he called affect programs, the inherited central mechanisms that direct behaviour. He assumed that all human beings were born with a set of nine basal affects. Each affect motivated behaviour that helped us meet our very essential needs and to communicate our needs to others. Each affect program was composed of a bodily experience, an impulse to act and a potential for communication to others. Tomkins did not believe that the affect programs had a special place in the brain, but rather that many areas of the brain were activated when an emotion was triggered.

\section{The nine innate affects}

According to Tomkins, the nine innate affects elicit exclusive biological responses in the brain in three distinct patterns: an increase, a decrease or a steady state pattern of brain activity. Each time a stimulus elicits an affect, the brain gets ready for the next affect to be triggered. An innate affect lasts only milliseconds. The affect system is a general system and does not take into consideration what kind of stimulus causes the affect. Affects are categorised and felt as positive/rewarding, negative/punishing or neutral. Positive affects make us motivated to stay in the affect and help it continue. The meaning of Interest/excitement is to make learning rewarding. It has an increasing stimulus pattern. Enjoyment/joy has a decreasing stimulus pattern, making us calm after activation. The affect Enjoyment/joy is therefore always preceded by another affect that can be either positive or negative. The neutral affect Surprise/startle motivates neither avoidance nor continuation. Its trigger produces rapid increased brain activity and then rapid decreased activity and it makes us stop and pay attention to something new. Negative affects motivate us to make the affect stop and avoid the stimuli. Fear/terror is associated with a very strong increase in brain activity, which motivates us to stop what we are doing straight away and handle the emergency at hand. This affect elicits fleeing or freezing behaviour. Distress/anguish has an above optimal steady state pattern of brain activity. It makes us want to get help and try to discontinue something that is uncomfortable and disturbing. Anger/rage also has an above optimal steady state pattern but the brain activity is much stronger than for distress and the need to change whatever is not good greater. According to Tomkins, Disgust (to expel noxious items, also socially) and Dissmell (to ward off and avoid noxious items, also socially) evolved as protections against hunger drives. In an evolutionary 
perspective, according to Tomkins, Shame/humiliation is the last affect to develop. It evolved through the need to motivate us to attend to what causes the impediment of joy or interest. Evolutionarily, there is a need to maintain a healthy balance between positive and negative emotion.

Silvan Tomkins' primary contribution to the understanding of affect was to define the nine innate affects as neurobiological mechanisms when the affective system is working as intended, thus disregarding affective malfunctioning and dysregulation, which undoubtedly constitute important quantities of affective life. In his work he reveales how affects are activated in accordance with the given stimulus and deactivated when the focus of attention on the triggering event has occurred. Consequently, he did not take aberrations into consideration. When affects are avoided, dysregulated or subdued, they may lead to psychological malfunction and hinder goal seeking and development. In line with clinical affect theory, Nathanson (2008) argues that depressive disorders are characterized by such irregularities of normal affect management when the ability to mobilize positive affect is reduced or the capacity to turn off distress-anguish is diminished. These affective abnormalities constitute psychological malfunction (McCullough Vaillant, 1997).

\section{Affect, feeling and emotion}

In Tomkins' theoretical understanding, distinctions are made between the terms affect, feeling and emotion. The nine affects are innate and universal. A feeling is felt when the individual becomes aware of the affect. Tomkins stipulates that the affects and their resulting feelings are inborn parts of the human biology. Emotions, however are culturally and familially dependent since affects are dealt with differently, encouraged in one family and supressed in another. As a result, each individual has a unique learning history and an emotional script on how to handle the naturally elicited affects

\section{Theories on basic emotion}

Research in the field of neuroscience has yielded new knowledge on the purpose of and importance of emotions in the developing child, in human functioning generally as well as across species (Alcaro \& Panksepp, 2011; Davis \& Panksepp, 2011; Panksepp, 2011). Basic emotion theory stipulates that discrete emotions are subcortical. They are fast and automatic reactions to stimuli that are outside of conscious awareness. These responses need to generalize to successfully deal with challenges and opportunities that humans have had to deal with since ancient times. Emotions are seen as the very primary processes that give us knowledge crucial for survival and therefore 
set forward secondary processes such as learning and memory as well as tertiary processes of cognition (Panksepp \& Watt, 2011).

Although there is great consensus among many researchers about the existence of basic emotions, the disagreement concerns how many and which emotions are to be considered as primary. Levenson (2011; Tracy \& Randles, 2011) presents one of the purest lists of basic emotions and presents Enjoyment, Anger, Disgust, Fear, Surprise and Sadness as basic emotions. Each of these has a distinctive functionality and behaviour repertoire linked to it. When we enjoy ourselves, we play; when we feel anger, we fight; when we feel disgust, we reject; when we feel fear, we avoid; when we feel surprise, we re-orientate; and when we feel sad, we seek help. In Levenson's model, three additional emotions are considered basic although the support for distinctiveness and hard-wired brain circuits is not as evident. These emotions are of utmost importance to human thriving and survival. Relief/content, which brings soothing; Interest, which make us explore; and Love, which results in attachment. In Ekman's conceptualization of emotion families (Ekman \& Cordaro, 2011), the basic emotion sadness belongs to an emotion family with shame, guilt, distress and anguish as family members.

Panksepp and Watt (2011; Tracy \& Randles, 2011) recognize seven basic emotional systems, which they argue exist across species: Seeking, Fear, Rage, Lust, Care, Panic and Play (playfulness). In humans these systems are crucial for mental health but when dysregulated, also the cause of mental disorders. Panksepp describes the seeking system as one of the most generalized motivational systems involved in all the other emotional systems. According to Panksepp, the seeking system is what other behaviour theorists have mislabelled as the brain's reward system and he links it to attachment issues (Alcaro \& Panksepp, 2011).

\section{Emotion and cognition}

Panksepp argues that it is important to separate basic emotions from cognition (Panksepp, 2011). The brain processes information bottom up from emotion to cognition but also top down from higher structures down to subcortical areas of the brain. It is crucial to understand that on the primary process level, emotions are not under the control of cognition and it is the ancestral brain's speaking, its language wired for survival and adapted through evolution to create the best conditions for our existence (Panksepp, 2012). At the secondary and even more so at the tertiary level, cognition is more involved in emotion processes. Here, for example, we can think about to whom we direct our anger and why we feel sad and if the reason is sensible. The question of whether emotions require cognition has been widely discussed. Levenson (2011) notes that one first has to define cognition to answer such a question. If by cognition, we mean "anything that the brain 
does" (p. 384) it is obvious that emotion follows cognition. However, if we mean cognition that requires more awareness in the form of planning, control and reasoning, Levenson argues that there is no need for cognition to elicit a basic emotion. Instead, emotions precede cognition.

We are born with individual differences in the capacity for physiological self-regulation, which in turn affects the quality of care experiences early in life. Hence, both temperamental aspects as well as early experiences with caregivers influence the emotional response, although its development is also a function of the maturation of cortical regulatory areas (Thompson, 2011). Thompson shows how cognitive and emotional development are closely linked in the growing child Emotional arousal and self-regulation are influenced by the maturation of attentional systems that enable voluntary control, e.g., of looking behaviour and thus the ability to terminate looking when emotionally aroused. Cognitive appraisals of situations that elicit emotions, e.g., fear of heights or of strangers, develop during the first year. Also, emotions linked to reaching or not being able to reach a goal arise through both motoric development and cognitive awareness. Later in the second year, self-conscious evaluative emotions such as pride, guilt and shame that are linked to the child's appraisal of others' evaluation starts to develop. During the third year, consciousness about self and others continue to develop as the child starts to differentiate between her own thoughts and the thoughts of others, in what is usually called theory of mind/mentalisation. Emotion regulation is thus important for our well-being and for our ability to adapt to our environment.

The close link between emotion and cognition is also seen in the effect that emotions have on learning and memory. In an experiment by Singer and Fagen, two-month old infants were taught to kick in order to move a 10 -item mobile. When the mobile was taken away, half of the babies cried. One week later, the babies who did not cry remembered how to kick to make the mobile move, whereas the babies who did cry couldn't remember well enough to make it move (Singer \& Fagan, 1992). It seems like the emotional arousal obstructed the learning process.

The Differential Emotion Theory (DET) postulates that each discrete emotion always has a motivational but also a regulatory function (Izard et al., 2011). In DET, emotional knowledge (EK) consists of two central concepts: understanding of expressions and the functions of emotion utilization (EU) and emotion regulation (ER). EU is the process of making adaptive use of emotional arousal. ER is the neural, cognitive and behaviour processes that make us tolerate, increase or reduce emotional arousal. As these functions develop, the growing child's social behaviour repertoire improves. Language development plays an important role in the maturation of EK and ER. The ability to symbolize and give names to the inner experience of emotions helps 
us differentiate emotions from each other. In turn, this capacity assists us in the process of understanding and managing emotions.

\section{Emotion and developmental psychology}

Emotions are associated with motivation and distinctive goals. Very early emotional expressions are associated with the infant's effort to maintain or stop stimulation that is enjoyable or unpleasant. A baby cries when hungry or cold, gazes at a new interesting object or smiles during a social interaction. Neural and neuroendocrine arousal systems, e.g., the hypothalamic-pituitaryadrenocortical axis (HPA-axis) are already functional at birth and develop continually during the first years of life. Through the maturation of the brain, the child's emotional lability declines and greater self-control arises. Not only maturation with age, but also caregivers' responsiveness and attunement to the child's experience, affect the capacity to endure stress and to selfregulate (Thompson, 2011).

Genetic programs, such as the affect program, can be either open or closed. Although affects are pre-programmed and involuntary, they adjust through the individual's own experiences and the environment's responses to the individual's emotional expression (Ekman \& Cordaro, 2011). In this sense, affective programmes are seen as open and can be changed during the lifetime of the individual because information is let into the program, which has the potential to change its course. Because humans have a long period of parental care, there is time for learning, which makes open programs advantageous. In this sense, humans have the opportunity to learn the best way of reacting in a specific environment. Parents respond to the child's emotional reactions and show their own emotional repertoire. New emotional behaviours are continuously aquired throughout life and adapted to the preset affect program. Therefore, our bodily reactions and impulses that act on an emotion are both evolutionary and individual, modelled by cognition and voluntary action. When the new experience of response is entered into the affect program, it will then be automatically changed just as if it had always been there. Despite the plasticity of the affect programs, our ancestral inherited basic emotions are not easily changed because this would make us more vulnerable to challenges/threats and opportunities in our environment that are linked to our survival.

There are cultural differences in the value and expression of emotions. Therefore, parents shape their children's emotional repertoire into what is socially acceptable in the specific environment, by interacting with the child with facial expressions, bodily contact and language (Halberstadt \& Lozada, 2011). Through caregivers ability to meet the infants attachment behaviour, children develop the capacity to regulate emotions. Affects can thus motivate 
healthy, adaptive behaviour but they can also lead to unhealthy, maladaptive behaviour.

\section{Other theories of emotion}

Theories on emotions are abundant and the many attempts to explain the origin and function of emotion have increased with the new techniques that the study of neuroscience enables. Although we have gained new knowledge of the function of the brain and the processes involved in affective reactions, agreement on what constitutes an emotion and on the role of emotional processes is no closer to being reached (LeDoux, 2000). Differences in perspectives and on the questions asked complicate the picture further. Not everyone agrees with the notion that emotions are innate, universally expressed and exclusive in their biological responses (Iacoviello et al., 2007). The theory of constructed emotions argues that humans construct the world with their emotions instead of emotions being reactions to triggers in the world. Emotional responses are believed to be created in the moment of experience and influenced by our previous learning history (Barrett Feldman, 2017). In this view the brain's main function is to regulate all bodily systems. By interoception the brain senses the status of all internal systems whereby the subjective experience is pleasant or unpleasant and the physiological response is arousal or calmness. Barrett argues that from this point our experience decides what this sensation means. In this theoretical framework, we construct concepts to make sense of the incoming sensory input. Consequently, each individual plays an important role in creating his or her emotional life.

\section{Emotion regulation}

Emotion regulation and dysregulation figure significantly in mental health and illness and most disorders involve some form of emotion dysregulation (Gross \& Barrett Feldman, 2013; Gross \& Levenson, 1997). An obvious example is depressive disorder, characterized by a deficit of positive emotions. Emotion regulation in its most basic form involves inhibition of emotional expression, and healthy adults often inhibit their emotions for adaptive purposes. Nevertheless, inhibiting expressive emotional behaviour can lead to dysfunction and, most obviously, decrease the experience of the emotion; hence the motivational impact of the affect may be lost. Gross explains emotion regulation as "attempts to influence which emotions one has, when one has them and how one experiences or expresses these emotions." (Gross \& Levenson, 1997, p. 95). Thus, emotion regulation is aimed at influencing emotions. A more elaborate description implies a process of self-soothing that influences the duration, intensity, or 
composition of emotional and physiological pressure. The process modulates attention, motivation, and behaviour in an effort to adapt to circumstances and to achieve set goals (Thompson, 2011).

Thompson (Thompson, 1994) defines emotion regulation as the individual's external and internal processes aimed at acknowledging, evaluating and modifying their emotional reactions. In this conceptualization, emotion regulation is not equal to emotional control. Rather, it is problems in experiencing and discriminating the whole range of emotions and hence responding in accordance with them that may be as maladaptive as the capacity to downregulate strong emotions. Emotion regulation difficulties may occur when efforts are made to control emotional experiences and expressions (Tull, Gratz, Salters, \& Roemer, 2004). Gross and John showed that undergraduate students who were asked to suppress positive emotions experienced and expressed fewer positive emotions, whereas suppression of negative emotions decreases the expression of negative emotion but not the experience of those emotions (Gross \& John, 2003). Experimentally, it has been shown that constricting and concealing emotions when watching films with emotion eliciting stimuli (either positive or negative) will lead to less expression of the emotions but greater physiological activation, especially when supressing negative emotions (Gross, 1998a; Gross \& Levenson, 1997). Difficult emotions carry important information and must be experienced despite the discomfort (Hayes, Wilson, \& Strosahl, 1996).

\section{Phobia for affects/experiential avoidance}

The basic concepts of activating and inhibitory affects provide a framework for understanding problem behaviour in the affect phobia model. Adaptive activating affects (positive feelings for self, grief, anger/self-assertion, pride, closeness, healthy fear, sexual feelings) motivate the person to approach various actions, whereas inhibitory affects (shame, guilt, pain, disgust, and anxiety) function to inhibit various actions (McCullough Vaillant, 1997). These two systems need to be in balance. For example, a person should be able to activate and fully experience a grief response without too much inhibitory pain; to be able to assert one's self with less accompanying anxiety; and to feel guilty in an adequate proportion when doing wrong.

Experiential avoidance, conceptualized as the tendency to avoid negative internal experiences, including emotional experiences, bodily experiences and cognitions (thoughts and memories), has been widely acknowledged as a cause for psychological and behavioural problems (Hayes \& Strosahl, 2004; Linehan, 1993) and has been suggested as a functionally diagnostic dimension for psychopathology (Hayes et al., 1996). Hayes believes 
experiential avoidance to be one of the unifying functions of many forms of psychopathology, highly prevalent in diagnosis such as substance abuse, OCD, panic disorder and borderline personality disorder but also prevalent in many other diagnoses. Phobia of affect, or emotional avoidance, is a somewhat narrower concept focusing singularly on emotional avoidance. It constitutes a central target for various forms of psychotherapeutic methods (Davanloo, 1980; Fosha, 2000; Greenberg, 2012; McCullough, Kuhn, Andrews, Kaplan, et al., 2003; McCullough Vaillant, 1997). In gestalt therapy, many psychological problems are understood as resulting from avoidance of painful feelings or fear of unwanted emotions (Perls, Hefferline, $\&$ Goodman, 1994). Some literature suggests that an accepting stance towards one's own emotions promote healthier behaviours and enhanced functioning, in contrast to when the individual experience negative emotions in response to their own emotional reactions (Hayes et al., 1996; Linehan, 1993). Conscious access to our emotions and the ability to reflect upon them seem to be important strategies for successful emotion regulation (Gross, 1998b, 2013). Greenberg accentuates that emotions promote meaning and action as well as communication and that emotions need to be processed rather than controlled to access their full adaptive purpose (Greenberg, 2012).

Thus, adaptive emotional functioning entails modulation of emotion instead of elimination of undesired emotions (Tull et al., 2004). It is evident from the litterature that emotional avoidance and emotion regulation are two concepts that share many similar implications.

\section{Sense of self/ sense of others}

While there is no agreement as to what exactly the self is, it is considered to be a central aspect in psychology, and the subjective experience of having a self is natural for most people (Stern, 1985). The self refers to cognitive and affective representations of the individual's identity and subjective experience, of memories and experiences, and the inner knowledge of how one thinks and reacts in certain situations. Bowlby theorized that children develop expectations of their primary caregivers based on the caregiver's responses to them (Bowlby, 1988). In turn, these expectations synthesize into internal working models of self and others, which then are generalized onto other attachment relationships later in life. McCullough views sense of self and others as affectively based attachment complexes (McCullough Vaillant, 1997). 


\section{Substance Use Disorder}

Substance use disorder (SUD) is a serious disorder with large consequences for the individual and for society. Although the total alcohol consumption of the Swedish population has decreased since 2005 and consumption levels among teenagers are at an all time low, alcohol continues to be one of society's most serious problems causing great suffering for both adults and children. Nearly $6 \%$ of the Swedish population are estimated to either be dependent on or abuse alcohol (CAN The Swedish council for information on alcohol and other drugs, 2017). Every year, several thousand people in Sweden die due to alcohol related diseases and injuries. Alcohol-intoxicated persons often commit physical assaults. Seventy percent of the assaults against men and 36 percent of the assaults against women follow this pattern. Alcohol is involved in about 30 percent of all fatal accidents in Sweden, e.g. in traffic and at sea. The total societal costs due to alcohol are estimated to be somewhere between 20 and 80 million SEK per year (CAN- The Swedish council for information on alcohol and other drugs, 2010)

The portion of the population who have tried illicit drugs has remained relatively unchanged during the last 15 years, after a rise in the previous decade. At present, some indications show that drug use may have intensified among young adults. In 2016, $17 \%$ of 18 -year-old students in secondary school reported that they had tried drugs at some time; $3 \%$ had done so 20 times or more. Likewise, there was an increase in serious drug use during the 1990s. However, the most problematic types of drug use are more difficult to measure, but available indicators such as hospitalisation statistics, cause of death statistics and crime statistics suggest that the situation has deteriorated somewhat further in the 2000s (CAN, 2017).

\section{Classification of substance use disorder}

According to the American Psychiatric Association's classification system (DSM-5), substance use disorders are defined as behavioural, cognitive and physiological results of repeated substance use (American Psychiatric Association, 2013). The diagnosis covers 11 different criteria, which correspond to different substances. Thus, patients are diagnosed with "Alcohol Use Disorder", "Cannabis Use Disorder", and so forth, depending on the substance dependence:

1. Taking the substance in larger amounts or for longer than you meant to

2. Wanting to cut down or stop using the substance but not managing to

3. Spending a lot of time getting, using, or recovering from use of the substance 
4. Cravings and urges to use the substance

5. Not managing to do what you should at work, home, or school because of substance use

6. Continuing to use, even when it causes problems in relationships

7. Giving up important social, occupational, or recreational activities because of substance use

8. Using substances again and again, even when it puts you in danger

9. Continuing to use, even when you know you have a physical or psychological problem that could have been caused or made worse by the substance

10. Needing more of the substance to get the effect you want (tolerance)

11. Development of withdrawal symptoms, which can be relieved by taking more of the substance

The DSM-5 distinguishes the severity of SUD depending on how many symptoms are identified. Two or three symptoms indicate a mild substance use disorder; four or five symptoms indicate a moderate substance use disorder; and six or more symptoms indicate a severe substance use disorder.

\section{Etiology of alcohol use disorder}

The etiology and development of alcohol use disorder (AUD) is complex and diverse. The progress and cause of AUD is multifaceted with hereditary, personal and environmental aspects impacting its development. Several attempts have been made to develop an empirically grounded typology of alcohol dependence (Leggio, Kenna, Fenton, Bonenfant, \& Swift, 2009), but consistent evidence of their relevance has not yet been produced (Babor \& Caetano, 2006). All typologies have demonstrated an ability to identify relatively homogenous groups, but examination of their diagnostic validity and matching to treatment is yet to be recognized (Hesselbrock \& Hesselbrock, 2006). The most well-known two-type models are the distinctions Type I - Type II (Cloninger, 1981) and Type A - Type B (Babor, 1992). These two models are quite similar. Type $\mathrm{I} / \mathrm{A}$ is characterized by later onset, less-severe symptoms of alcohol dependence, less-severe psychopathology, and drinking with the desire to avoid harm. Type II/B is characterized by more severe symptoms of alcohol dependence, more severe psychopathology, more familial alcoholism, and drinking for pleasure. However, two-group solution typologies do not seem to fully capture clinical and general samples (Hesselbrock \& Hesselbrock, 2006). Two four-type cluster solutions with similar subtyping, examined within two different samples are 1: Mild course, Polydrug, Negative affect, and Chronic/Antisocial personality disorder (Windle \& Scheidt, 2004) and 2: 
Chronic/Severe, Depressed/Anxious, Mildly affected, and Antisocial (Hesselbrock \& Hesselbrock, 2006). Thus, in the four-type clusters comorbidity with affective and anxiety symptoms are highlighted.

People with AUD are at high risk for having comorbid psychiatric disorders. The most frequent disorders are mood disorders, anxiety disorders and personality disorders (Petrakis, Gonzalez, Rosenheck, \& Krystal, 2002). In the Swedish Lundby study (Brådvik, Mattisson, Bogren, \& Nettelbladt, 2010) an extensive comorbidity between depression and alcohol dependence was found and both conditions showed comparably equal significance for commission of suicide. In spite of broad comorbidity, treatment programs for alcohol dependence do not commonly include combined treatment addressing psychiatric difficulties. The debate has been long whether AUD causes psychological problems or whether psychological difficulties cause problems with alcohol. There is evidence that excessive alcohol use increases the risk for depression, anxiety and sleep disturbances (CAN, 2010). However, there is also research showing that personality pathology and conduct disorder in early adolescence predicts later alcohol problems (Cohen, Chen, Crawford, Brook, \& Gordon, 2007). In a Dutch study, risk factors for developing alcohol dependence were early onset of anxiety symptoms and depression (Boschloo et al., 2011). The plausible conclusion seems to be that the causal relation between alcohol use disorder and psychological disorders can go in both directions.

\section{Neurobiology}

The reward system in the brain is triggered by natural pleasure, such as sex, food and social affiliation and plays a vital role in the survival of the species, but it is also essential for problems arising from SUD. The system begins in the ventral tegmental area (VTA), and projects to the nucleus accumbens (NACC) and the frontal cortex. In human imaging studies, decreases in dopaminergic function have been identified as a key element of addiction but other brain processes are also involved in the process (Koob \& Simon, 2009; Koob \& Volkow, 2016).

Continued substance use produces changes in brain functions that promote and sustain addiction and contribute to relapse. The addiction process is thought to involve a three-stage cycle: binging/intoxication, withdrawal/negative affect, and preoccupation/anticipation, i.e., craving. The cycle becomes more severe as the individual continues the substance use. Drug addiction has been conceptualized as a disorder that involves elements of both impulsivity and compulsivity. Repeated drug use will affect the brain so that the ability to regulate emotion will be affected (Koob \& Volkow, 2010) 
Current understanding of substance use disorder is the notion that the disease evolves through the interaction of the drugs themselves, genetic, environmental, behavioural and psychosocial factors.

\section{Treatment of SUD}

Treatment options for SUD include both pharmacological and psychosocial alternatives and a combination of interventions is most often recommended (National Board of Health and Welfare, 2015). Patients' goals for treatment range from total abstinence to controlled use. Current treatment guidelines on psychosocial interventions for SUD advocate cognitive behaviour therapy and other techniques that help enhance motivation to change and behaviour adjustment. These are motivational enhancement therapy, relapse prevention, community reinforcement therapy and social behaviour network therapy. However, several psychological treatments for SUD have empirical support. There are a number of approved pharmacological treatments for SUD that either manage withdrawal symptoms, reduce craving or decrease the rewarding effects of the substances' symptoms, e.g. naltrexone and acamprosate for AUD (disulfiram to establish sobriety) and buprenorphine or methadone for opiate substance use disorder (National Board of Health and Welfare, 2015).

\section{The role of emotion in substance use disorder}

The self-medication hypothesis of substance use disorder suggests that the use of alcohol and drugs are means to relieve painful affect, control affect when it is confusing or to activate affects when they are absent. Furthermore, alcohol is used as means to cope with difficulties regarding self-esteem, relationships, and self-care (Khantzian, 1997, 2003, 2012). The model extends from Kohut's supposition that addiction is a misguided attempt to regulate affect and repair the inadequate self-structure (Kohut, 1977). As such, substance use disorder becomes a self-regulation disorder. In a study comparing patients with SUD and comorbid mood or anxiety disorders, SUD alone and a control group, the comorbid sample reported substance use to achieve or maintain feelings of euphoria, control anger, alleviate boredom, increase creativity and to feel comfortable in performance situations (Bizzarri et al., 2007). Not only the comorbid group but also the SUD only group reported self-medication with substance use to deal with emotions and psychiatric suffering.

Research on drinking motives has conceptualized drinking to cope and drinking to enhance to be internally driven efforts to change one's internal emotional experience, in contrast to external reasons for drinking: conformity 
and for social purposes (Cooper, 1994). Both drinking to cope, that is, drinking to avoid unpleasant emotional states or symptoms, and drinking to enhance have been associated with high alcohol intake and the risk of developing problematic drinking behaviour (Cooper, Frone, Russell, \& Mudar, 1995; Kuntsche, Knibbe, Gmel, \& Engels, 2005). In a British cohort of adolescents 17-18 years of age $(n=3957)$, self-reported alcohol use and drinking to cope motives were assessed. These were: to help when feeling nervous, to feel more self-confident and sure of yourself, to relax, to forget worries, to cheer up when you're in a bad mood, to help when you feel depressed and to help when your mood changes a lot. Four groups emerged. Those who reported few coping motives, those who reported confidence motives and relaxation, those whose drinking was motivated by wanting to cheer up and help lift depression and those who reported drinking to cope with all sorts of emotional experiences. Strong associations with anxiety or depressive disorder were found in this latter generalized motives group, where adolescents were six times more likely to have a high risk-drinking pattern (Stapinski et al., 2016).

High alcohol intake has been associated with emotion regulation difficulties (Dvorak et al., 2014). In a study with 200 American college students, the aim was to investigate if drinking motives (conceptualized in the four-dimension model: drinking to cope, drinking to enhance emotional experience, drinking for social reasons and drinking to conform) (Cooper, 1994) mediated the link between emotion regulation deficits and problem drinking (Aurora \& Klanecky, 2016). The results showed that drinking to cope motives fully mediated the emotion regulation/problem drinking relationship and enhancement motives partially mediated the relationship. Thus, past research indicates that emotions play a central role in the development of alcohol related problems.

In a study using the Emotion-Regulation Skills Questionnaire (ERSQ), it was found that tolerance of negative affect was the one emotion regulation aspect that negatively correlated with alcohol consumption (Berking et al., 2011).

\section{SUD on shame and guilt}

Feelings of shame relate to the individual's own perception that they are flawed or that others have that same belief while guilt signals to the self that we have done something wrong or hurtful (Luoma, Guinther, Potter, \& Cheslock, 2017). The self-medication hypothesis also theorizes that substance use is a way of dealing with problems of self-esteem and self-care. These concepts are closely linked to shame, a feeling that has been found to be a risk factor for the development of SUD, as it leads to avoidant coping behaviour with substance use and social withdrawal (Dearing, Stuewig, \& 
Tangney, 2005; VanDerhei, Rojahn, Stuewig, \& McKnight, 2014). In Nathanson's view, drug and alcohol use is seen as means of managing shame (Nathanson, 2008). In this view, shame serves as an antecedent to SUD.

Equally, shame and guilt feelings are consequences of substance use, since the addictive behaviour is hurtful for the individual and to their close kin, which leads to secondary feelings of shame and guilt. Thus, the problematic feeling become twofold and the need to subdue painful feelings intensified. In a study examining psychological predictors of drinking behaviours in 89 adults, shame and guilt were both found to be predictive of alcohol consumption, and alcohol related problems but shame had the greatest influence on problematic drinking (Luoma, Kohlenberg, Hayes, \& Fletcher, 2012). In relapse prevention, the latter mechanism of shame (as a consequence of addiction) is conceptualized as the abstinence violation effect (Marlatt \& Donovan, 2005). The Fletcher study also showed a difference between guilt proneness and guilt experiences, the former being related to less problematic drinking and the latter to more problematic drinking.

\section{Psychotherapy for SUD}

Psychological treatment is defined as methods or techniques aimed at changing and working through the individual person's maladaptive behaviour, both regarding the substance use and other initial problems starting before and possibly leading to substance abuse. A number of psychological treatments for AUD have shown enough evidence to be recommended for use, such as Relapse Prevention (Marlatt \& Donovan, 2005) and Motivational Interviewing (Miller \& Rollnick, 2002). The list of psychological treatments with empirical support also includes psychodynamic therapy as well as interactional psychotherapy, a therapy which targets immediate feelings and explores patients' relationships (Brown \& Yalom, 1977). The effectiveness of psychotherapy for other substance use disorders have shown less support (National Board of Health and Welfare, 2015).

The major efficacious therapeutic mechanisms or principles for treatment of AUD are still unclear. Berglund and colleagues (Berglund et al., 2003) show that even evidence-based combinations of pharmacological and psychological treatments still leave a large proportion of patients without significant improvement. Previous studies that have provided empirical support for psychological treatments have focused on insight and emotional experiencing, that is, trials including psychodynamic therapy (Ojehagen et al., 1992; Sandahl, Herlitz, \& Ahlin, 1998) and interactional therapy, a group therapy developed by Irwin Yalom and adapted to alcohol dependence (Brown \& Yalom, 1977). Interactional therapy has been tested in several randomized controlled studies with positive results, although there are no 
significant differences in comparison to CBT (Cooney, Kadden, Litt, \& Getter, 1991; Kadden, Cooney, Getter, \& Litt, 1989; Kadden, Litt, Cooney, Kabela, \& Getter, 2001; Litt, Babor, DelBoca, Kadden, \& Cooney, 1992).

Acceptance and commitment therapy uses a combination of acceptance, mindfulness, and values-based therapeutic processes to gain higher psychological flexibility. This entails stepping back and mindfully watching inner experiences, i.e. thoughts, feelings, and bodily sensations. The goal is to learn more accepting and mindful ways of relating to inner experiences, rather than engaging in substance use as reactions to craving or negative affect, that is, emotional avoidance. A meta-analysis of 10 randomized controlled trials of ACT for SUD favoured ACT over CBT, 12-step programmes and treatment as usual (Lee, An, Levin, \& Twohig, 2015). Also, a short intervention of ACT targeting shame resulted in fewer days of substance use and elevated utilization of residential treatment compared to patients who did not receive the adjunctive ACT group intervention (Luoma et al., 2017).

The factors that individuals with SUD themselves rate as most important to successful recovery include decreased substance use, increased ability to regulate emotion, increased positive interpersonal relations, and increased levels of self-esteem (Nordfjaern, Rundmo, \& Hole, 2010).

One of the greatest challenges in conducting treatment in general and psychosocial treatment specifically for patients with SUD is to keep patients in treatment. In a meta-analytic review of psychosocial treatment for SUD, around one third of the patients dropped out before treatment was completed. This was true independent of treatment format or type of drug use, but patients with comorbid psychiatric diagnosis had higher dropout rates (Dutra et al., 2008).

\section{The role of emotion and sense of self in dynamic psychotherapy}

In psychoanalytic theory and practice, the view of emotions has developed from Freud's drive theory to Kohut's self-psychology. In Kohut's understanding, the ability to regulate emotions is seen as an essential part of the development of the three main types of self-object needs: mirroring, idealizing and twinship. These needs are crucial for growth of a consistent sense of self which matures in the experiences of the caregiving situation (Kohut, 1971, 1977). Research on attachment theory (Bowlby, 1988) puts forth further evidence of the importance of the caregiver in relation to innate motivational forces in regard to security and exploration, which also drive important biological needs for interpersonal closeness. The attachment system's main function is to regulate closeness to the caregiver when danger 
and stress appear, offer comfort and security (safe haven) and develop a secure base from which to explore the world. The caregivers' responsiveness and attunement to the child's experience affect their capacity to endure stress and to self-regulate. A further development in regard to emotion in dynamic psychotherapy is the experiential dynamic psychotherapy tradition in which emotions are seen as a primary source of motivation as depicted in affect theory and attachment needs as another (Fosha, 2000; McCullough Vaillant, 1997).

\section{The role of emotion and cognition in dynamic psychotherapy}

A meta-analysis examined the impact of eliciting affect in psychotherapy and found an association between therapists facilitating patients' affective expressions and outcomes in psychodynamic psychotherapy (Diener et al., 2007). In a review of the psychotherapy process-outcome research literature, Orlinsky, Ronnerstad, and Wilutzki (2004) suggested that even though experiencing emotion in therapy sessions has strong effects, outcomes might be dependent on how effectively therapists recognize and work with these expressions.

In emotion focused experiential psychotherapy methods like Affect Phobia therapy (APT), Emotion Focused Therapy (EFT), Accelerated Experiential Dynamic Therapy (AEDP) and Intensive Short Term Dynamic Psyhchotherapy (ISTDP), emotions are viewed as the central guiding force that determines how a person functions in their world (Davanloo, 1980; Fosha, 2000; Fosha, Siegel, \& Solomon, 2009; Greenberg, 2012; McCullough, Kuhn, Andrews, Kaplan, et al., 2003; McCullough Vaillant, 1997). Therapeutic change occurs through directly accessing and working with problematic emotional experiences in therapy sessions and changing maladaptive emotional processes. Emotional processing refers to how an individual accesses and becomes aware of their emotional experience, accepts the experience, places meaning on it, and transforms maladaptive emotions into adaptive ones. Emotional processing thus involves a combination of innate sensorimotor experience, the processing of emotional schematic memories, and processing on abstract cognitive levels (Greenberg, 2012; Greenberg \& Safran, 1987).

Cognition is of utmost importance in emotional processing since there is a need to be aware of, reflect on and find meaning in our emotions, in order to work with the problematic emotional experience. It has been proposed that for individuals with depression, it is the accessing and deepening of emotional processing ability that allows patients to take adaptive action to meet their needs (Greenberg \& Watson, 1998). 


\section{Short-term dynamic therapy}

Short-term dynamic psychotherapy (STDP) has its origin in psychoanalytic psychotherapy and was developed during the ' 70 s and ' 80 s by psychoanalysts such as David Malan, Peter Sifneos and Habib Davanloo (Davanloo, 1980; Malan, 1976; Sifneos, 1979). STDP applies fundamental psychoanalytic principles for describing and understanding the dynamics and problems that patients bring to therapy. The idea is to use active interventions and transfer the control of the therapy process into the hands of the therapist (Malan, 1976), thus accelerating exposure, and then persistently confront defences (Davanloo, 1980) to uncover emotions and thoughts that interfere with patients' relationships and daily functioning (McCullough Vaillant, 1997). The foundation of STDP has been provided by Malan's two triangles; the triangle of conflict and the triangle of person (Malan, 1979). The conflict theory originates from Freud's structural theory of the Id, the Ego and the Super Ego and the unconscious influence of a person's inner structure.

The designated goals of treatment in STDP are to help the patient recognize defensive behaviour (insight), evoke the desire to change the maladaptive responses (motivation), viscerally experience the conflicted feeling (exposure) and adaptively express those feelings (new learning). In the process, there is a need to regulate the patient's anxiety or inhibition in the session.

\section{Affect phobia therapy}

Affect Phobia Therapy (APT) is characterized by high therapy activity; focus on emotion that promotes quicker progress, and an interest in the patient's patterns of relating to others. APT was developed by Leigh McCullough (McCullough et al., 2003; McCullough Vaillant, 1997) and is based on the principles of psychodynamic conflict theory, i.e., defence, anxiety and hidden emotions. The treatment integrates techniques and theories from other areas of psychotherapy both for further understanding of the patient's psychodynamic needs (e.g. clinical aspects of affect theory) and for working them through. Behavioural principles such as exposure and desensitization as well as gestalt therapy methodology such as guided fantasy are used for accelerating change while reducing anxiety. Clinical aspects of affect theory are integrated, as the therapy method embraces the idea that affects can motivate healthy, adaptive behaviour but can also lead to unhealthy, maladaptive behaviour. Feelings of safety and emotional closeness to others as well as positive feelings toward the self are clinically relevant motivational aspects comprised in the model

The concept of affect phobia refers to an inner conflict in which a certain activating, adaptive affect triggers an inhibiting affect (anxiety, shame, 
emotional pain), which pushes the individual toward a defensive or avoiding behaviour in order to get rid of the painful affects. The defensive behaviour can also be an expression of an affect. Extensive use of such defensive strategies comes at considerable cost (e.g., lack of intimacy, loneliness, somatic problems, lack of energy, inflexible behaviour patterns, and substance/alcohol abuse). The avoidant behaviours are regularly maladaptive because they block the individual from utilizing inherently adaptive affects, and they often constitute what we refer to as psychiatric symptoms or problematic behaviours (McCullough et al., 2003).

In APT the focus is on recognizing and understanding the mechanism of the defences and then relinquish them in order to restructure affects to facilitate experiencing, regulation and expression of affects. In therapy, the patient is gradually exposed to feelings that are avoided and trained to better regulate feelings that are too dominant in their lives. The goal of treatment is that the patient more frequently will be guided by their feelings towards a more adaptive behaviour repertoire.

McCullough and co workers acknowledge a set of specific treatment objects as the active ingredients in APT. These significantly coincide with the important change mechanisms theoretically and clinically in Short-Term Dynamic Psychotherapy generally and they clearly represent common factors across therapies. Insight refers to how clearly patients can recognize their maladaptive cognitive schemas or defensive behaviour. Motivation refers to how much the patient wants to give up the maladaptive or defensive behaviour. Exposure refers to how much bodily arousal of feeling is experienced in the session. Inhibition refers to how much anxiety, guilt, shame, or emotional pain is elicited in this process. New learning refers to how effectively the patient is able to express these feelings interpersonally outside the session. The Achievement of Therapeutic Objectives Scale (ATOS) is a scale designed to assess patients' attainment of these same treatment objectives, reflecting the results of a search for the active ingredients in treatment (McCullough, Bhatia, Ulvenes, Berggraf, \& Osborn, 2011). The ATOS scale was designed to assess patients' degree of absorption of specific treatment objectives. The idea is that when a therapist provides psychotherapy for a patient, the effect of that psychotherapy cannot be determined unless one observes a range of patient responses that indicate that treatment has made an impact on the patient (McCullough, Kuhn, Andrews, Hatch, et al., 2003).

APT has successfully been tested for personality disorders in two randomized controlled trials (Svartberg, Stiles, \& Seltzer, 2004; Winston et al., 1994). The treatment reduced psychiatric symptoms and increased personality functioning as well as social adjustment. A randomized controlled trial on self-help based APT delivered over the internet to participants with 
mood and anxiety disorders showed significant improvements on both depression and anxiety outcome measures (Johansson et al., 2013). Attempts have previously been made to deliver APT in a group therapy format for patients diagnosed with depression at Modum Bad hospital, an in-patient clinic in Norway. The treatment consisted of group therapy twice a week and an individual session per week for eight weeks, but the treatment has not been empirically evaluated (B.L., personal communication, September 2013).

Several therapeutic orientations have acknowledged that emotional avoidance is a common feature in many individuals with psychological problems and psychiatric symptoms (Hayes et al., 1996). Even though the two concepts of emotional avoidance and affect phobia have many similarities, they also differ somewhat. In the affect phobia frame, emotions are seen as either activating or inhibitory and all affects have the potential to be adaptive or maladaptive, i.e. avoidant and unregulated (McCullough et al., 2003; McCullough Vaillant, 1997).

\section{Sense of self/self-compassion, sense of others/closeness}

The APT model emphasis self- care and self-forgiveness, thus asserting that warm feelings towards oneself are adaptive feelings that may often be avoided. The construct of sense of self in APT includes degrees of the empathetic and realistic quality of patients' experience of an adaptive selfimage (McCullough \& Andrews, 2001; Schanche, Stiles, McCullough, Svartberg, \& Nielsen, 2011), including self-understanding and self-care. Selfcompassion is a closely related concept that tries to capture a compassionate self-to-self relating when confronted with personal suffering (Neff, 2003) which can be related to abundant feelings of guilt and shame. Neff and McGehee (2010) propose three important components in self-compassion: (1) self-kindness, which is to treat oneself with care and understanding, instead of with intense self-critique, (2) realizing that one's imperfection is a shared experience with all other humans and (3) being mindful in the present moment instead of overreacting in regard to one's own life experiences of suffering.

Sense of others involves one's views of others, that is, whether the experience and understanding of others can be open, compassionate and realistic but with healthy boundaries and interdependence (McCullough et al., 2003). Adaptive sense of self and sense of others are needed for the ability to develop and sustain close relationships with others and maintain a balance between autonomy and closeness.

Self restructuring and self other restructuring are the processes in APT in which exposure and response inhibition to phobias related to sense of self and others are worked through. When problems in these areas are abundant, defence and affect restructuring is not possible. A week sense of self and 
others involves either devaluation or idealizing views of self/others or a combination of both. Hence the individual possess a poor ability to see one's own and others' strengths and weaknesses in a balanced and realistic manner. Often there can be great discrepancies in a person's views and demands of themselves versus others.

\section{ADHD}

Attention deficit hyperactivity disorder (ADHD) is a common neurodevelopmental disorder that persists into adulthood in the majority of cases, with adult prevalence estimated at between $2.5-4.3 \%$ (Kessler et al., 2006). ADHD is diagnosed when criteria for the core features of inattention, hyperactivity and impulsivity are fulfilled (American Psychiatric Association, 2013).

It has been repeatedly reported that childhood ADHD is associated with negative outcomes across the lifespan, as individuals with ADHD are more likely to experience educational and occupational under-achievement, lose jobs, get divorced, and have more accidents and poorer health (Barkley, Anastopoulos, Guevremont, \& Fletcher, 1991). Interpersonal problems are overrepresented in adults with ADHD (Wilens et al., 2005; Wilens \& Dodson, 2004). Common symptoms and consequences of ADHD in adulthood are lack of motivation, mood lability, anxiety, depression and low self-esteem (Able, Johnston, Adler, \& Swindle, 2007), and the comorbidity with other psychiatric disorders is high. The development of ADHD symptoms in children is influenced by a complex interaction between genetics and environmental factors. In a study with adopted children (Harold et al., 2013), ADHD symptoms of the biological mother significantly predicted a child's impulsivity and activation at age 4.5. This predicted maternal hostility from the adoptive mothers and ADHDsymptoms in children at age 6 .

\section{The role of emotion in $A D H D$}

A shared factor amongst the deficiency symptoms in individuals with ADHD is poor self-regulation. Most recently, emotional dyregulation has come into focus (Corbisiero, Stieglitz, Retz, \& Rösler, 2013; Skirrow \& Asherson, 2013), although emotional symptoms in the ADHD population have been known since the first descriptions of the functional impairment (Surman et al., 2013). In Wender, Utah, criteria for ADHD in adults' seven symptom areas are described, four within the symptom description in DSM (poor attention, disorganization, hyperactivity/restlessness and impulsivity) and three emotionally oriented (temper, affect lability and emotional over reactivity) (Marchant, Reimherr, Robison, Robison, \& Wender, 2013; Ward, 
Wender, \& Reimherr, 1993). Barkley theorizes that dysfunctional selfregulation of affects and high arousal is present in the ADHD population because of a developmental delay in the capacity to inhibit responses (Barkley \& Murphy, 2010).

According to Nathanson (2008), the two affects that dominate the clinical picture in ADHD are interest-excitement that is inadequately mobilized and/or maintained, and hypersensitivity to shame-humiliation. In a study examining 71 biographical narratives from undiagnosed individual who later received ADHD diagnosis, feelings of failure, lack of self-confidence, descriptions of functional difficulties, stress and guilt feelings were prominent (Fleischmann \& Fleischmann, 2012). In cognitive psychotherapy for patients with ADHD, it is recognized that negative social feedback from parents and peers can produce distorted negative thoughts, which in turn may lead to negative emotions and avoidant behaviour (Knouse \& Safren, 2010).

\section{$A D H D$ and SUD}

ADHD is particularly prevalent in individuals with substance use disorders (SUD). A recent meta-analysis reported an ADHD prevalence rate of $23.1 \%$ in SUD (van Emmerik-van Oortmerssen et al., 2012). ADHD affects the course and severity of SUD and has been associated with adherence to treatment problems, higher rates of relapse and longer and more intensive treatment to reach treatment goals (Ohlmeier et al., 2008; Wise, Cuffe, \& Fischer, 2001). Early age temperamental characteristics found to be associated with later onset of SUD are fearfulness, accident proneness and having frequent temper tantrums (Nogueira et al., 2014). The high comorbidity between ADHD and SUD may reflect common genetic dispositions. Furthermore, continuous drug use will affect the brain so that the ability to regulate emotion will be further impaired (Koob \& Volkow, 2010). The comorbidity hypothesis regarding the association between ADHD and SUD argues that novelty seeking and comorbid externalizing disorders likely play a role in the initiation of substance use. But when substance use has begun, drug and alcohol intake are used as means to alleviate the core ADHD symptoms of attention deficits and hyperactivity. Thus, self-medication perpetuates SUD (Young \& Sedgwick, 2015).

One of the key elements in ADHD symptomatology concerns impulsivity (Kessler et al., 2006). Difficulties in controlling impulsive behaviours when faced with emotional distress have been linked to risky drinking. Studies on drinking to cope demonstrate that motivation to deal with dysregulation of emotion concerns drinking to enhance positive feeling as well as drinking to alleviate negative emotional states (Cooper, 1994). The dysregulation of emotion and self in this comorbid patient group may involve two 
motivational pathways. As an entrance into problematic drinking and drug use, both sensation seeking behaviour and enhancement of positive affect appear to be at play. Furthermore lack of impulse control and difficulties in handling stress and frustration seem to drive substance use problems,, which has been shown both in SUD populations as well as in the comorbid SUD and ADHD population (Young et al., 2015; Young \& Sedgwick, 2015). Hence, the comorbid ADHD and SUD patient group may be greatly affected by emotional laden dysregulation difficulties associated to both ADHD and to SUD in relation to the abuse.

\section{Psychotherapy for ADHD}

Psychotherapeutic interventions for ADHD most frequently address functional impairments in everyday life and include psychoeducation, learning strategies and skills. Cognitive behaviour therapy (CBT) (Emilsson et al., 2011; Safren et al., 2005), dialectical behaviour therapy (DBT) based treatment (Hirvikoski et al., 2011), and meta-cognitive therapy (Solanto et al., 2010) are frequently applied treatments, and group formats are common. There is preliminary evidence that psychological treatments that specifically target emotion dysregulation in ADHD are efficacious (Mongia \& Hechtman, 2012; Sonuga-Barke et al., 2013).

Evidence for usefulness of psychosocial treatment in adult ADHD is inconclusive (Philipsen et al., 2015) but in combination with pharmacological medication there is evidence of efficaciousness (Skokauskas, McNicholas, Masaud, \& Frodl, 2011). In a randomized controlled trial with 419 patients, cognitive behaviour group treatment (GPT) was compared to clinical management $(\mathrm{CM})$ for twelve weeks and thereafter every month for nine months. In addition, patients in the study received either central stimulants or a placebo (Philipsen et al., 2015). The results showed that pharmacological treatment was effective for core symptoms of ADHD and after three months, $\mathrm{CM}$ appeared superior to the structured group treatment, but long-term effects favoured GPT, especially when measuring patients' general wellbeing, coping skills, self-esteem and acceptance. Although psychiatric comorbidity, self-devaluation and interpersonal difficulties are widely acknowledged in ADHD, few studies have investigated psychotherapies targeting these problems. Studies on psychological treatment specifically targeting ADHD and SUD are lacking. Due to the uncertain results from several trials evaluating pharmacotherapy in the comorbid ADHD and SUD population (Konstenius et al., 2014; Konstenius, Jayaram-Lindström, Beck, \& Franck, 2010; Levin et al., 2006, 2015; Levin, Evans, Brooks, \& Garawi, 2007; Schubiner et al., 2002), other treatment possibilities are needed. 


\section{Common factors}

\section{Alliance and other relationship factors}

There is an abundance of research examining the therapeutic alliance, and it is regarded as one of the principal curative common factors in psychotherapy. Meta-analyses have shown an average correlation of .27 between alliance and psychotherapy outcome, a moderate but robust finding across studies (Horvath, Del Re, Flückiger, \& Symonds, 2011). Bordin's definition focuses on three domains: agreement of the goals of treatment, agreement on the tasks of treatment and the quality of the interpersonal and emotional bond between patient and therapist (Bordin, 1979). Measures of alliance in group therapy often describe alliance, not only with the therapists or with specific members of the group, but also with the group as a whole (Lindgren, Barber, \& Sandahl, 2008). Other relationship factors that have found support in research are empathy, goal consensus and collaboration, positive regard and affirmation, congruence/genuineness, collecting client feedback, repairing alliance ruptures and managing countertransference (Norcross, 2011).

Current understanding of psychosocial treatment in general and psychotherapy research specifically gives support for therapist empathy as one of the central ingredients. In meta-analysis this client factor has been shown to have a moderately strong relationship to therapy outcome (Elliott, Bohart, Watson, \& Greenberg, 2011). In addiction treatment, empathy is linked to higher treatment success whereas low empathic skills have been associated with larger drop-out rates and greater relapse rates (Moyers \& Miller, 2013).

\section{Role expectations and other client factors}

A long held assumption in psychotherapy is that if the patient's expectations are congruent with the method and style of the treatment, the therapy has a better chance of attaining satisfying treatment results (Duckro, Beal, \& George, 1979). Research on role expectations and/or disconfirmation of role expectations has primarily focused on the variables retention (continuation of psychotherapy), outcome at termination and therapeutic alliance. Disconfirmation of role expectations is mostly defined as the discrepancy between patient and therapist role expectations (Constantino, Arnkoff, Glass, Ametrano, \& Smith, 2011). Confirmation of role expectations has been seen as one of the factors that facilitate the development of the therapeutic alliance. Knowledge about factors that can facilitate the psychotherapy 
process for individuals with substance abuse is essential, since relapse and dropout is frequent in this group (Clarkin \& Levy, 2004).

There is evidence that clients make the single strongest contribution to outcome in psychotherapy (Bohart \& Greaves Wade, 2013). Severity of problem, comorbidity, access to emotion, level of self-critique, and attachment style, are some of the aspects related to client factors that make a great contribution to outcome. Client's motivation for change is one of the driving forces in psychotherapy. APT acknowledges that motivation grows from the experiential understanding that therapy will make a change in the patient's every day life (McCullough Vaillant, 1997) In MI, change talk motivates and helps the patient to implement the new behaviour (Miller \& Rollnick, 2002).

\section{Aims}

\section{General aim}

The overall aim of the present research was to explore the role of affects in psychotherapy for SUD. Further aims were to investigate affect-focused orientations, importance of common factors and a measurement of affect phobia.

\section{Specific aims}

Study I aimed to examine how the discrepancy between patients' treatment expectations prior to psychotherapy and experience of on-going psychotherapy correlated with the therapeutic alliance for patients with substance use disorders. The hypothesis was that a confirmation of patients' expectations would be associated with a higher level of alliance while a disconfirmation of patients' expectations would be associated with a lower level of alliance. Another aim was to test whether different dimensions of role expectations predicted retention in psychotherapy.

Study II aimed to make the first evaluation of the psychometric properties of the Affect Phobia Test. The three specific objectives were to provide basic reference data on the Affect Phobia Test for a clinical sample of patients with depression and/or anxiety and a non-clinical sample of university students, to test reliability in terms of internal consistency and test-retest reliability and to evaluate the validity of the test with regard to discriminative validity and factor structure. 
Study III aimed to make a first preliminary investigation of whether APT was a feasible and helpful first-line treatment for patients diagnosed with mild to moderate alcohol use disorder and problematic affective avoidance/emotion regulation difficulties.

Study IV aimed to evaluate the feasibility and analyse preliminary data of effectiveness of affect phobia group therapy for patients with comorbid substance use disorders and ADHD with core features of affect phobia/emotion dysregulation.

\section{Methods}

\section{Study I}

\section{Design and procedure}

Data were part of a naturalistic study of psychotherapy among patients with substance use disorders - Matching and Outcome of Psychotherapy at Addiction Clinics in Sweden (MOPACS). Data collection occurred between 2006 and 2009. All patients were treated in the Stockholm Center for Dependency Disorders, a large public-sector addiction clinic that provides specialized care for SUD for the inhabitants of the major part of Stockholm County, Sweden. When giving their informed consent, patients were requested to complete a questionnaire including socio-demographic data, alcohol and drug use as well as the measures described below. Additional questionnaires were sent by post to all patients in the study within six months after therapy had commenced. Waiting time from assessment to therapy start was less than three months for 82 per cent of the patients, 11 per cent waited between three-six months and seven per cent had a waiting time longer than six months.

\section{Participants}

In all, 159 patients took part in Study I. They were all outpatients with various substance use disorders. About two thirds had alcohol as their primary substance and one third various illicit drugs. The most frequent comorbid psychiatric disorders were mood disorders, followed by anxiety disorders and personality disorders. The mean age was 43.6 years and $55 \%$ were women. In total, $87 \%$ had Sweden as their country of birth and $88 \%$ had a high school education. The main occupation for $50 \%$ was either work or studies. 


\section{Measures}

\section{Self-report measures}

\section{Psychotherapy Expectations and Experiences Questionnaire - Short (PEX-S)}

Treatment expectations prior to therapy and experiences of therapy were measured with the Psychotherapy Expectations and Experiences Questionnaire - Short (PEX-S) developed by Clinton and Sandell (2003). PEX can be used both by patient and therapist before, during and after treatment. It measures expectations of what might be helpful in therapy (PEX1) as well as experiences of therapy (PEX2). The instrument is based on an interaction hypothesis stating that different therapy methods match different patients. The hypothesis is that the working alliance between patient and therapist is enhanced when their answers on the PEX are concordant or converge over time (Clinton, 2001; Clinton \& Sandell, 2003). PEX-S consists of 25 items (the original version have 50 items) distributed over five subscales. Answers are given on a 6-point Likert scale and scored from 1(“disagree completely") to 6 ("agree completely"). The five subscales are: External Orientation, interventions focusing on practical tasks and problem solving (e.g. "I think I would be helped by focusing on concrete problems"). Internal Orientation: interventions focusing on reflection and inner processes (e.g. "I think I would be helped by reflecting on hurtful memories"), Catharsis: interventions focusing on expressive, emotionally charged material, (e.g. "I think I would be helped by expressing sadness and anger"), Support: interventions focusing on encouragement, confirmation and sympathy, (e.g. "I think I would be helped by being met with kindness and consideration"), Defensiveness: interventions focusing on avoiding uncomfortable confrontation (e.g. "I think I would be helped by repressing unpleasant feelings and thoughts"). The psychometric properties of the PEX in its original version are satisfactory, with high reliability in terms of internal consistency for the five subscales of PEX: Internal Orientation: $\alpha=$ .86; External Orientation: $\alpha=.89$; Catharsis: $\alpha=.87$; Support: $\alpha=.83$; Defensiveness: $\alpha=.85$ (Clinton \& Sandell, 2003).

\section{Working Alliance Inventory - Short (WAI-S)}

Working alliance was measured with the Working Alliance Inventory-Short (WAI-S) consisting of 12 items (Tracey \& Kokotovic, 1989), derived from the original 36-item version (Horvath et al., 2011). WAI-S is a widely used instrument. Tracy and Kokotovis demonstrated adequate reliability of the WAI-S: internal consistency for the overall client score was $\alpha=.98$. Two 
different versions of the WAI-S were used: in individual therapy with questions about the relationship between patient and therapist and in group therapy with questions about the relationship between patient and the group as a whole.

\section{Data analysis}

For each subscale in the PEX-S, a measurement of the discrepancy between role expectations prior to therapy and experiences during treatment was created. The discrepancy measure was labelled REED (Role Expectations and Experiences Discrepancy). REED was operationalized as the squared euclidic distance between each individual patient's mean value on the subscales in PEX1-S and PEX2-S, for example (Catharsis 1 -Catharsis $\left.{ }_{2}\right)^{2}$. The higher the value obtained, the greater the discrepancy between role expectations and experiences of psychotherapy. The five subscales were then summarized as REED total: (External Orientation ${ }_{1}$ - External Orientation $\left.{ }_{2}\right)^{2}+$ $\left.\left(\text { Internal Orientation }_{1} \text { - Internal Orientation }\right)_{2}\right)^{2}+$ (Support $_{1}-$ Support $\left._{2}\right)^{2}+$ $\left.\left(\text { Catharsis }_{1}-\text { Catharsis }_{2}\right)^{2}+\left(\text { Defensiveness }_{1} \text {-Defensiveness }\right)_{2}\right)^{2}$. For the sake of comparability, parametric methods were employed throughout the study. An exception was the analysis of the associations between the PEX1-S subscales and therapy retention (which was on an ordinal level), for which Spearman's rho and partial Spearman correlations were used. The association between the REED and WAI-S was analysed using Pearson correlations.

\section{Study II}

\section{Design and procedure}

Study II was a psychometric study on the Affect Phobia Test, which was translated from English into Swedish in a method called "parallel" or "committee" translation. One experienced researcher and one experienced psychotherapist translated the questionnaire independently. The translation was then compared in a group setting where a third experienced researcher/psychotherapist participated and the translation was discussed until consensus was reached.

The clinical sample was collected from patients participating in a randomised controlled trial of internet-based, affect-focused treatment (Johansson et al., 2013). Patients were recruited via the internet and advertisements in newspapers and the Affect Phobia Test was answered online. Out of the 82 patients, 38 were on a waiting list control group and they completed the questionnaires twice, with a two-week intermission, comprising a validation sample that enabled a test-retest measurement. The university student sample was collected in three universities situated in two 
Swedish cities, Stockholm and Linköping. The students were asked to complete the questionnaire in conjunction with seminars that they attended.

\section{Participants}

The clinical sample consisted of 82 patients. The mean age was $45.9,84 \%$ were women and $67 \%$ were married or living with a partner. The university student sample of 197 individuals had a mean age of $26.4,77 \%$ were women and $58 \%$ were married or living with a partner.

\section{Measures}

\section{Affect Phobia Test}

The Affect Phobia Test is used for screening patients for affect phobia (McCullough, Berggraf, \& Ulvenes, 2010) and consists of 20 items distributed over seven dimensions. Answers are given on a 5-point Likert scale and scored from 1 ("Not at all") to 5 ("Very much") (The total score can be in the range of 20-100). The seven dimensions are: Anger-Assertion, Sadness-Grief, Attachment-Closeness/Tenderness, Sexual Feelings, Positive feelings for the self, Interest-Excitement, and Enjoyment-Joy (with three questions on all domains except Sexuality with two questions).

\section{Data analysis}

The analysis included internal consistency in terms of Cronbach's alpha and test-retest reliability (for a subsample of the patient group), factor analysis for examining the factor structure and calculation of an empirical cut-off.

\section{Study III}

\section{Design and procedure}

Study III had a multiple baseline design and took place at Stockholm Center for Dependency Disorders in a naturalistic setting. Written information about the study was sent to two outpatient clinics. The information stated inclusion/exclusion criteria for participating in the project. When referrals were made, the therapist met the patient to give information about the study and the therapy method and to ensure that the inclusion criteria were met. Inclusions were made until the study sample was completed. 


\section{Participants}

Three women with mild to moderate alcohol use disorder participated in Study III.

\section{Measures}

In Study III PEX-S and the Affect Phobia Test were used, measures already described in Study I, except for the psychometric properties of the latter, which is described below. In addition the following measures were used:

\section{Affect Phobia Test}

The psychometric properties of the Swedish version of the Affect Phobia Test show satisfactory reliability in terms of internal consistency (Clinical sample $\alpha=0.88$; University students $\alpha=0.84)$ and test-retest $\left(\mathrm{r}_{\mathrm{xx}}=0.70\right.$ for the total scale) (Frankl et al., 2016).

\section{Outcome Questionnaire-45}

Outcome Questionnaire-45.2 (OQ-45.2) has a primary function of tracking patient progress during administration of psychological and drug treatments for psychological disorders. The aim is to describe patients on three specific levels: psychiatric symptoms (loading heavily on anxiety and depression), interpersonal relationships, and social role functioning (Lambert et al., 1996). The Swedish translation has shown good psychometric properties (Wennberg, Philips, \& de Jong, 2010).

\section{Outcome Questionnaire-10}

Outcome Questionnaire-10.2 (OQ-10) consists of 10 questions derived from the OQ-45 and is used as a brief screening instrument to follow patients' progress and alert of psychological distress (Lambert et al., 1996).

\section{Drug Calendar/Timeline Follow Back (TLFB)}

Timeline Follow Back or Drug Calendar (TLFB) is used for collecting the patient's retrospective estimation of his or her use of alcohol and illicit drugs day by day backwards in time (Fals-Stewart, O'Farrell, Freitas, McFarlin, \& Rutigliano, 2000; Sobell \& Sobell, 1992).

\section{Penn Alcohol Craving Scale}

Craving was measured with the Penn Alcohol Craving Scale (PACS) (Flannery, Volpicelli, \& Pettinati, 1999), a self-report questionnaire 
consisting of five items on one scale with questions about the frequency, intensity, and duration of cravings, the ability to resist drinking, and a question about the overall craving for the previous week. Answers are given on a 7-point Likert scale and scored from 1 ("Never) to 7 ("Almost always") (The total score of PACS can be in the range of 0-34). Flannery and colleagues demonstrated adequate reliability of the PACS; internal consistency was $\alpha=.92$.

\section{Data analysis}

The development of alcohol use and craving parameters during baseline, treatment, and follow-up were presented graphically. Statistical analysis using chi-square was conducted to calculate differences on two of the alcohol-related measures. Changes in craving over the treatment period were calculated with separate regression lines for each subject with time in therapy as the independent variable and craving, measured with PACS, as the dependent variable. Pre-to-post symptom changes on measures that were used at inclusion and at follow-up were also presented without statistical calculation.

\section{Study IV}

\section{Design and procedure}

Study IV had an open design and took place at Stockholm Center for Dependency Disorders in a naturalistic setting. Written information about the project was sent out to psychiatrists working at the clinic. The psychiatrist responsible for planning the patients' care made referrals to the study. The study coordinator met the patient for a screening visit to give oral and written information about the study and the treatment and to ensure that the inclusion and exclusion criteria were fulfilled. The patients were then scheduled to provide drug/alcohol tests at the unit for two weeks (once a week) to show stability in abstinence. If the tests proved to be negative, a new appointment for inclusion in the study was scheduled (maximum of six weeks and minimum of one week before treatment start) at which the patient filled in self-ratings measurements and the baseline periods were organized.

From inclusion to the start of treatment, patients participated in weekly measurements (conducted via telephone by a nurse). Hence, the length of baseline measurement period varied from patient to patient depending on referral and practical considerations in the naturalistic circumstances of the study but in the time frame described above. Inclusions were made until the study sample was completed. Measurements were carried out once a week 
from baseline period to end of treatment, at follow up four weeks after the end of treatment and six months after the end of treatment.

APT was adapted to a structured group format from manualized individual APT, and with influences from ADHD skills training and self-help group format. The treatment was conducted by two therapists and consisted of a 90-minute long welcome meeting, 14 weekly sessions of 180 minutes each, and one follow-up session four weeks after the end of treatment. At almost every weekly session, a new affective theme was introduced and focused on in the psycho-educational part of the session (for further description see appendix in article IV).

\section{Participants}

Twenty-two patients with SUD, 10 women and 12 men, participated. Twelve had alcohol use disorder, three mainly cannabis dependency, four mainly central stimulant dependency and three mainly opiate dependency. Only two patients had no comorbid psychiatric diagnoses other than ADHD. The most common diagnosis was anxiety disorders and depression. Two patients had bipolar type II, two had eating disorders, four had personality disorders (antisocial and borderline personality disorder), two had PTSD and two had learning disorders. The mean age was 41 years. In total, 91\% had Sweden as their country of birth, $54 \%$ had a high school education and $10 \%$ had higher education. Thirty-two percent were employed, $32 \%$ were unemployed, $10 \%$ were currently studying, and $30 \%$ were on temporary or permanent sick leave. Marital status was defined as either living on their own, which was true for $64 \%$ of the patients, or living with a partner. Central stimulants were the most common medication prescribed to 12 patients, followed by antipsychotics and mood stabilizers prescribed to six patients. Antidepressant medication was prescribed to five patients and pharmacotherapy for SUD including AUD to three of the patients. For anxiety and sleeping problems, three patients were prescribed antihistamines and one patient was prescribed sleeping pills.

\section{Measures}

In Study IV the Affect Phobia Test, OQ45/OQ10, WAI-S group and TLFB were used, as was the case in the first three studies. In addition, the following measures were used:

\section{Self-Compassion Scale}

The Self-Compassion Scale (SCS) measures six positive and negative factors of self-compassion: self-kindness, self-judgment, common humanity, 
isolation, mindfulness, and over-identification. The 26 questions are rated on a 5-point Likert-scale ranging from 1 (almost never) to 5 (almost always). The SCS has proven good internal consistency reliability for all subscales, from alpha of 0.75 to 0.81 for the factors and 0.92 for the total SCS. The measure has demonstrated construct validity using measures of social connectedness, perfectionism, emotional intelligence, anxiety, depression, and life satisfaction (Neff, 2003).

\section{Brown ADD scale "Managing affective interference"}

The Brown Attention-Deficit Disorder subscale "Managing affective interference" is used to assess emotion regulation. It has seven questions and answers are given on a 4-point Likert scale scored from 0 ("Never") to 3 ("Every day") (The total score can be in the range of 0-28) (Brown, 1996).

\section{VAS-scale for craving}

The VAS-scale for craving was used for estimation of craving the preceding seven days including today, and involves a rating on a scale from 0-100.

\section{VAS-scale for satisfaction and learning}

The VAS-scale for satisfaction and learning in session was used, and involves a rating on a scale from $0-100$.

\section{Client Satisfaction Questionnaire}

The Client Satisfaction Questionnaire-8 is used to assess client satisfaction with treatment (Attkisson \& Greenfield, n.d.).

\section{Other rater}

The Clinical Global Impression and Improvement questionnaire (CGI) (Guy, 1976), with three question on severity of symptoms and clinical improvement, was used by the therapist.

\section{Screening instruments}

AUDIT was used for assessing the severity of alcohol problems (Berman, Wennberg, \& Källmén, 2012).

DUDIT was used for assessing the severity of drug problems (Berman, Bergman, Palmstierna, \& Schlyter, 2005; Berman et al., 2012).

Screening for drug use was done through laboratory analyses of urine. 
The laboratory analysis of blood used was Carbohydrate-Deficient Transferrin (Sharpe, 2001), which reflects the average alcohol consumption during 1-4 weeks prior to testing. Reference interval $>2.0 \%$ indicates heavy drinking.

SCID I Module E was used for assessing SUD in accordance with DSM-IVTR (American Psychiatric Association, 1994).

SCID II self-report form was used for screening patients with regard to personality disorders in accordance with DSM-IV-TR Axis II (American Psychiatric Association, 1994).

MINI was used for assessing other Axis I disorders in accordance with DSMIV-TR (American Psychiatric Association, 1994).

\section{Data analysis}

Descriptive statistics were used to illustrate change patterns from inclusion, session 2-8 and session 9-15. Comparisons between mean differences were examined using paired t-tests (pre-post). The statistical analysis was done with SPSS version 23. Due to missing data, analysis of the baseline period was not possible.

\section{Ethical approval}

All studies were conducted with permission from the Regional Ethics Committee in Stockholm, Sweden. The clinical sample in Study II was taken from a study with approval from the Regional Ethics committee in Linköping University Hospital, Linköping, Sweden. All patients provided informed consent before participating in the studies.

\section{Results}

\section{Study I}

For patients in group therapy, an overall discrepancy between role expectations and experiences was significantly related to a lower level of therapeutic alliance $\left(r_{\mathrm{xy}}=-0.55 ; p<.01\right)$. Particularly high negative correlations between REED and WAI-S were found on the subscales REED External Orientation $\left(r_{\mathrm{xy}}=-.62 ; p<.01\right)$ and REED Catharsis $\left(r_{\mathrm{xy}}=-.74 ; p<\right.$ $.001)$ for the group therapy patients. For patients in individual therapy, REED 
was not significantly Expectations characterized by defensiveness correlated negatively with therapy retention $\left(r_{\text {rho }}=-.30 ; p<.001\right)$. This association was statistically significant even when controlling for waiting time for therapy $\left(r_{\text {rho.z }}=-0.30 ; p<0.001\right)$.

\section{Study II}

There were significant gender differences in adaptive affective functioning on the total score and on the affective domains Sadness/Grief, Attachment/Closeness and Joy in the university student sample. Women scored higher, that is, had better ability to experience and express affects compared to men. No gender difference was found in the patient sample.

The internal consistency for the total score was satisfactory (Clinical sample $\alpha=0.88$; University students $\alpha=0.84$ ). For the affective domains, the internal consistency was satisfactory $(\alpha>0.70)$ for all domains except Anger/Assertion (Clinical sample $\alpha=0.44$; University students $\alpha=0.36$ ), Sadness/Grief (Clinical sample $\alpha=0.24$; University students $\alpha=0.46$ ) and Attachment/Closeness (Clinical sample $\alpha=0.67$; University students $\alpha=$ 0.69). Test-retest with a two-week interval was conducted on a subsample $(\mathrm{N}=38)$ of the clinical sample. Test retest reliability was satisfactory $\left(\mathrm{r}_{\mathrm{xx}}>\right.$ 0.70 ) for the total score as well as for all the affective domains except for the domain Sadness/Grief $\left(\mathrm{r}_{\mathrm{xx}}=0.60\right)$.

An exploratory factor analysis was conducted. The factor solution only moderately matched the test's original affective domains because some items loaded on the "wrong" factor and some loaded on more than one factor. The exploratory factor analysis (principal component factor analysis with varimax rotation and Eigenvalue $>1 ; \mathrm{KMO}=0.82$ ) resulted in a six-factor solution.

To test the discriminative validity of the Affect Phobia Test, a t-test comparing the clinical sample with the university student sample was conducted. The clinical sample had significantly more affect phobia (i.e. lower total scores on the test) compared to the university student sample $(t=7.5 ; \mathrm{df}=233 ; \mathrm{p}<0.0001)$. To calculate an empirical cut-off between the clinical and the university student sample, we used the formula, $\mathrm{c}=$ $\left(\mathrm{s}_{0} \mathrm{M}_{1}+\mathrm{s}_{1} \mathrm{M}_{0}\right) /\left(\mathrm{s}_{0}+\mathrm{s}_{1}\right)$ (Jacobson \& Truax, 1991), which yielded a cut-off of 72 points.

\section{Study III}

When analyzing the results as measured with self-report questionnaires and a weekly calendar of alcohol consumption for each patient, the results give mixed findings. The primary outcome measure Heavy Episodic Drinking (HED) and secondary outcome measure Days of Consumption (CONS) were analyzed for the three patients as a group using chi-square tests across the 
four phases of treatment (four weeks prior to therapy, therapy sessions 1-5, therapy sessions 6-10, and four weeks of follow-up) using all daily ratings, that is 126 days per patient ( 378 ratings in total). There was no significant difference in heavy episodic drinking across the time periods. There was a difference in days of consumption where days of drinking increased during the follow-up period (chi-square $=17.887 ; \mathrm{df}=3 ; \mathrm{p}=0.0001$ ).

Affect phobia was reduced for two of the patients, one reaching adaptive levels of affective behaviour at follow-up, as measured with the Affect Phobia Test. These two patients also showed significant symptom reduction as measured with OQ45 as well as decreasing levels of alcohol in their blood as measured with CDT.

PEX 1 showed that the patients expected therapy to be supportive, focused on reflection and inner processes, practically task-orientated, as well as focused on expressive, emotionally charged material. They did not expect therapy to avoid uncomfortable confrontation. PEX 2 showed that the patients experienced therapy as supportive and focused on reflection and inner processes. They experienced therapy as more focused on expressive, emotionally charged material and less on practically task-oriented material compared to their expectations. They did not experience therapy as avoiding uncomfortable confrontation.

\section{Study IV}

There was no change in psychological distress or in emotion regulation from inclusion to session 15 . There was a significant increase in self-compassion and decrease in affect phobia from screening to session 15.

Participation in session (the three patient group therapies merged) varied from 19 to 11 patients and participation in session decreased over time. Dropouts occurred continuously, but patients also failed to attend some of the sessions and then came back to later sessions. At session 6, 14 patients were still in treatment. Three of the patients participated in all 16 sessions. In the first part of the treatment from session 2 to session 8 , the participation varied between 13 to 18 patients. In the second part of treatment, from session 9 to 16 , the participation varied between 9 and 11 patients. Of the 9 women included in the study, 8 participated in 8 sessions or more whereas 6 of the 13 included men participated in 8 sessions or more. No pattern related to dropout related to sessions could be detected.

Satisfaction varied from 76.4 at session 2 to 92.5 at session 15 (end of treatment) and learning varied from 63.3 at session 2 to 91.2 at session 15 . There was an increase in both satisfaction and learning over the course of treatment, although ratings varied somewhat over different sessions. Apart 
from the ending session, session 9 with the theme guilt, had the highest ratings on both satisfaction and learning

At inclusion patients gave the lowest rating for craving, 20.6. Ratings of craving then varied across sessions but close to the end of treatment craving rose and reached its highest ratings. At follow up four weeks later, ratings had decreased again to the same level as early in treatment. At inclusion patients had a mean consumption of 3.7 standard drinks in a week, which meant that the patients on average drank every second day. More than $75 \%$ of their drinking days consisted of days with HED. During treatment patients had a mean consumption of $1.05(0.9+1.2 / 2=1.05)$ standard drinks weekly, which meant that patients on average drank once a week and $50 \%$ of their drinking days consisted of days with HED. Eight patients abstained from drinking during the whole treatment. Drug use was scarce and therefore could not be analysed in a meaningful manner.

Working alliance increased during the course of treatment from mean values of 4.9 at session 2 to 6.2 at session 15 , which was the ending session. Session 11 had the highest alliance rating and it focused on Interest/Excitement. To see whether the increase in alliance was due to dropout, analysis of ratings from the patients who participated in session (915) was compared to the whole sample and no difference was detected.

\section{General discussion}

\section{Reflection on findings}

\section{Affect phobia and its relation to psychiatric function}

Study II shows that a psychiatric population, i.e., individuals with depression and anxiety disorders, had more affect phobia and conversely less adaptive affective capacity compared to a student group. This result is in accordance with the theoretical assumption in APT (McCullough et al., 2003) i.e., repeated avoidant behaviours are maladaptive because they block the individual from utilizing the inherently adaptive affects, and lead to psychiatric symptoms or problematic behaviours. It is also in line with the literature on experiential avoidance stating that negative internal emotionally laden experiences is a cause for psychological and behavioural problems and should be considered a function diagnostic dimension in psychopathology (Hayes et al., 1996). Since depression and anxiety disorders are some of the most common psychiatric conditions, treatment options that target the problem area as well as further understanding of how phobic reactions to emotions impinge on the afflicted individuals has relevance. There is initial 
support that internet delivered APT based treatment is efficacious for depression and anxiety disorders (Johansson et al., 2013).

\section{Affect phobia therapy for substance use disorder}

Study III and IV indicate that patients with SUD and core features of affect phobia benefit from APT mainly in increasing adaptive affective functioning and self-compassion. Hence, adaptive use of affects and self-care seems to increase in relation to treatment. These aspects constitute the main treatment objectives in APT, thus showing that APT is a feasible and valid treatment for the patient group. However, on a group level the significant decrease in affect phobia for patients in Study IV did not reach levels of adaptive affective functioning, i.e. 72 points or more on the affect phobia test, a level that was empirically derived in Study II. Furthermore, prior to treatment, patients reported low levels of self compassion in comparison with other psychiatric populations (Neff, Whittaker, \& Karl, 2017) and the increase in self-compassion after completing treatment still left the patient group with substantial self-critical difficulties. Thus, it is evident that the patient groups studied in this thesis are greatly afflicted by psychological difficulties.

Concerning psychiatric symptoms in relation to affect phobia the studies give mixed results. In Study III psychiatric symptoms as measured with OQ45 decreased for the two patients that also gained better adaptive functioning in post therapy measurements. For the third patient the reverse association was found. i.e., slightly more self-reported affect phobia and more psychiatric symptomatology. In Study IV no significant decreases in psychiatric symptoms were found, although patients reported greater adaptive affective functioning after treatment. Perhaps the relatively short duration of therapy was not sufficient for symptom change to occur, especially related to function in everyday life, which the OQ-45 attempts to measure. Selfcompassion relates to how the individuals feel for themselves. The possible change toward greater well being related to higher levels of self-compassion is most probably longer and more complex process than can be detected in study formats like the present. Furthermore, the relatively small number of patients in the studies augments the probability that differences in treatment results were confounded by many factors. The case studies in Study III explicitly exemplify that individual differences between patients, diverse life situations for example, and lack of support from a partner may have great influence on treatment results. 


\section{Affect phobia therapy in relation to substance use}

Regarding the substance use related measures of consumption and craving, the results are also varied. In Study III the hypothesis that heavy episodic drinking would subside during the time in therapy did not hold true for all patients. Instead, the three patients had different trajectories of alcohol consumption and craving. Differences in treatment results may be due to the patients' level of dependency. A comprehensive assessment before starting APT treatment for patients with alcohol dependency is necessary and may result in recommendation of other treatment methods such as RP and MI or a combination of treatment modalities for enhanced treatment results. Also, longer treatment than ten weeks may be needed.

In Study IV patients shifted in their drinking pattern from frequent drinking consisting of mostly heavy episodic drinking to fewer drinking occasions comprising mainly social drinking. The result is promising, but due to the small number of patients, who individually had great differences in drinking patterns, this result should be interpreted with caution. Many of the patients maintained total abstinence during treatment and hence the results may not account for a reliable change related to treatment.

Ratings for craving of alcohol and drugs varied across sessions but increased towards the end of treatment. An interpretation of the result is that therapy coming to a close evoked anxiety and painful feelings that triggered craving. During treatment, some patients reported that in the process of approaching phobic feelings the defences - i.e. the urge to drink - became stronger, which is in line with the theoretical assumption of this thesis (McCullough et al., 2003; McCullough Vaillant, 1997). Thus, in working with defence relinquishing, therapy itself can elicit craving for drugs and alcohol and the therapist must remain cautious of this scenario. APTtreatment in itself does not contain strategies for deterring the patient from drinking and as the exposure to activating affects initially triggers anxiety, which in turn initiates defences, a suggestion is to incorporate additional safety structures in the treatment to ensure that exposure in treatment is balanced and always done together with anxiety regulation. Psychoeducation and skills building from relapse prevention (Marlatt \& Donovan, 2005) on how to handle craving could be integrated into the treatment. Since this is the first time APT was tested for SUD, many thoughts on how to improve treatment for the patient group have arisen. A suggestion on this note is to develop the treatment and add a session specifically targeting defence relinquishing on craving for alcohol or drugs in relation to adaptive activating affects. This session should be conducted early in the therapy, enabling repeated exposure opportunities as therapy progresses. Furthermore, detailed 
investigation into which affects evoke anxiety and trigger defences in the individual patient has to be done before starting the exposure.

The majority of patients in the studies had comorbid conditions with other psychiatric diagnosis. In Study IV, comorbidity was obligatory. As stated earlier, the self-medication theory of SUD proposes that alcohol and drugs are attempts to alleviate, control and activate affects (Khantzian, 2003). Khantzian describes substance use mainly as an effort to cope with selfregulation difficulties. Self-regulation problems may be especially pronounced in comorbid populations (Bizzarri et al., 2007).

In conclusion, APT helped reducing affect phobia and increase selfcompassion but concerning substance use and reduction of psychiatric symptoms short-term APT individually and in group has yet to prove its usefulness as a therapy that can help SUD patients abstain from substance use or to gain control over drinking.

\section{SUD and ADHD on guilt}

Ratings of satisfaction and learning in Study IV were both especially high in the session focusing on guilt. Feelings of guilt are common both in patients with SUD and patients with ADHD (Able et al., 2007; Luoma et al., 2017), and it may well be that recognition between patients regarding this feeling is abundant. The psychoeducational segments of the treatment facilitated understanding of guilt and normalized its presence in light of repeated failures in everyday life due to ADHD symptomatology and alcohol and drug use. In the APT group format, patients seemed to have been able to share the experience of guilt collectively with positive results.

The session prior to guilt focused on self-compassion, and a hypothesis is that the work which had been done in the previous session, helped in the process of handling guilt. Self-compassion entails being kind to oneself rather than making hard self-judgement, as well as recognizing that it is a human condition to make mistakes (Neff, 2003).

\section{SUD and ADHD on positive activating affects}

In Study IV, ratings on satisfaction and learning in session were generally high across the entire course of therapy and increased over time, following each other relatively closely in each session. For most sessions, satisfaction was rated slightly higher, but the reverse was true for sessions 13 and 14, which focused on sexuality and joy respectively. The notion that we can develop affect phobias toward positive emotions may not be easily understood at first glance. APT has a clear emphasis on reducing affect phobia for positive activating affects (McCullough et al., 2003; McCullough 
Vaillant, 1997), which might also be an unusual focus for the patients and, thus, in the group therapy new learning took place.

\section{Affect Phobia Group Treatment for SUD and ADHD}

Group treatment is a common therapeutic approach in targeting SUD and also in psychosocial treatment for ADHD. In the APT manual, self- and other-restructuring constitutes the starting point of treatment if the patient has low impulse control, high hold defences, lack of self-compassion, impaired relationships with others and/or low motivation for change (McCullough et al., 2003). In adapting the manual to a group format, the self and other concepts became vital. Another reason for the extra focus on self-compassion and relationships to others was that the targeted patient group had high comorbidity and high levels of social impairment. Interpersonal difficulties and social insecurity are common in adults with ADHD and constitute core features in the comorbid ADHD and SUD population (Wilens \& Dodson, 2004; Young et al., 2015). Still, psychotherapy with a focus on social relational issues for this patient group is unusual. Here, APT may be of use. All treatment sessions ended with patients reflecting aloud one at a time on what they had experienced during the session. One of the most common commentaries concerned positive feelings towards being part of the group and feeling understood by members of the group.

The patients in Study IV have multiple comorbid conditions and have been diagnosed with ADHD in adulthood, which means that their functional disabilities have been evident from an early age, alas without receiving the appropriate support. Their self-regulative capacity on all domains connected to ADHD is thus incapacitated. The high and increasing patient ratings on satisfaction and learning suggest that the treatment is a helpful and positive experience. Experiencing and expressing feelings in relation to loss of life opportunities, not being understood and receiving too little support from others is one of the important aspects of APT. For this specific patient group, sadness for having hidden dysfunctional cognitive and emotional capacities that through life have fed self-critique, shame and guilt feelings is crucial to express and share with others to increase life satisfaction. Fleishman \& Fleishman (2017) showed that adults with ADHD previously undiagnosed changed their views after being diagnosed, coming to believe that they could start leading more meaningful and manageable lives and that they ultimately even could benefit from having ADHD.

The incapacity that many patients revealed so clearly in not coming to treatment, although they described how meaningful and helpful the treatment was to them, became evident in Study IV. In conducting psychotherapy with this problem-ridden patient group, action must be taken to help patients stay 
in treatment. An obvious reason for this is that treatment seems to help those patients who complete, but another is that patients with ADHD commonly have a history of failure that creates feelings of guilt and shame, two of the most important affects that APT attempts to regulate. Success in completing the treatment from start to finish can, in itself, help patients feel confidence and pride. A suggestion would be to more explicitly tie specific social support to those patients who need help coming to the treatment sessions.

\section{The importance of self-compassion/positive feelings for self}

The Affect Phobia Test seems to capture one motivational affective system that has great relevance to APT and psychotherapy generally since it deals with self-related issues. Positive feelings for self has many resemblances to self-compassion (Neff \& McGehee, 2010). Conducting APT is dependent on the individual's capacity for positive feelings for self, since it will not be possible to work with defence relinquishing and affect restructuring if sense of self and sense of others are too fragile and the patient is using self-critique as a defence. This aspect is also important for estimations of the duration of therapy, since high levels of self-critique and misconceptions in relation to the possibility of receiving support will impede the APT treatment objectives.

In Study III there were differences between patients in level of adaptive positive feeling for self and others, which coincided with level of alcohol consumption. Mary and Michelle had high held defences and less trust in the therapist and would have needed longer therapies for restructuring the attachment related treatment objectives. Carey, on the other hand, quickly reached the main objectives of defence restructuring, affect experiencing and affect expression.

In Study IV, group session 11, which followed after the sessions with themes on guilt and shame, had the highest alliance rating. An interpretation of this result is that mutual recognition and sharing of the themes in the prior sessions had brought the group closer together. One goal of APT is to attend to the way the individual views themselves and feels about themselves, as well as to how they believe that others perceive them and lastly how they perceive others. When these self-other related feelings and perceptions are negative and maladaptive, therapy needs to focus foremost on building an adaptive sense of self and others. To do this in a group setting is both challenging and rewarding.

\section{Difficulties in measuring adaptive affective functioning}

The psychometric description of the affect phobia test in Study III shows that estimating the capacity for adaptive affective functioning holds some 
difficulties. Since emotions are culturally and individually defined, it complicates the understanding and communication of them. Hence, formulating questions that capture the adaptive/maladaptive dimensions of affects is challenging. Sadness and anger are especially problematic affects in the sense that they may feel negative and difficult to experience even when they function as adaptive triggers that focus the individual's attention towards the important stimuli. The affect phobia test attempts to capture both the raw experience of the affect and whether the emotional experience is felt to be helpful. For example, one can feel a lot of anger but still be afraid to, and unable to, adaptively use the affect as a tool for constructive self-assertion. Likewise, to be able to cry in front of someone and to feel sorrow about a loss does not have the same truly adaptive connotation as feeling relief from crying. Hence, it is possible to get high scores in the event of both experiencing and expressing adaptive grief and experiencing depressive/defensive sadness.

The multi-layered features of emotions complicate not only measuring affects, but also working psychotherapeutically with emotions. For example, anger and sorrow are affects that can easily be used as defence strategies against other affects. In self-report questionnaires as well as in psychotherapy, the difference between defensive and adaptive use of emotions might be missed. Furthermore, anger and sorrow are especially difficult to categorize as distinctly activating or inhibitory and adaptive or maladaptive. In some cases it is the interpersonal expression of affects, rather than the intrapersonal experience, that determines its adaptive value. What becomes important in therapy is to link the affective expression to cognition and gain the capacity to regulate the affect (Greenberg, 2012). As an example, activating anger can start as a rush of energy that triggers an action tendency, but when the individual fails to regulate the affect it can lead to uncontrolled anger and subsequently develop in the direction of threat and violence, thus becoming truly maladaptive (McCullough Vaillant, 1997).

In the exploratory factor analysis of the affect phobia test, items in the Attachment-Closeness/Tenderness dimension loaded on the same factor as Sexual feelings, whereas items in the Interest/Excitement dimension loaded on the same factor as items in the Enjoyment/Joy dimension. In Panksepp's description of basic emotions, these same emotions are theoretically related to one another in what he calls the Seeking system (Panksepp \& Watt, 2011), a positively coloured general motivation system where approach is rewarding. The exploratory factor structure points to the fact that relationally motivated seeking behaviours (Attachment-Closeness/Tenderness and Sexual feelings) are differentiated from materially motivated seeking (Interest/Excitement and Enjoyment/Joy). Furthermore, these four affective 
domains are the ones that most clearly can be described as both activating and positive, which probably contribute to the connection.

Clinically, it is valuable to work with the phobic affects that are particularly difficult for the individual patient, but the Affect Phobia Test does not manage to describe distinct affect phobias in the seven domains of the test and hence should be considered as measuring the degree of adaptive affective functioning as a whole.

\section{Further aspects}

\section{Therapeutic alliance}

Study IV showed that patients' alliance to the group as a whole increased over time and that learning and satisfaction with the treatment was high from the start and steadily improved as therapy progressed. The therapeutic alliance has proven to be an important common factor both in individual therapy and in group therapy, where the construct group cohesion often is used (Burlingame, McClendon, \& Alonso, 2011; Horvath et al., 2011). In Bordin's definition of therapeutic alliance (1979) the therapist's description of the rationale for therapy as well as negotiating tasks and goals becomes essential In experiential emotion focused psychotherapy like APT, a good therapeutic alliance facilitate working with attachment motivated aspects of the patient's psychological functioning, i.e. related to sense of self and sense of others. The therapist as a person and the bond between patient and therapist is of utmost importance in this process.

The main finding in Study I was that the greater the concordance between patients' expectations and what they experienced in group therapy, the stronger the alliance. In individual therapy, alliance ratings were higher and the variation smaller, which might explain the absence of significant results between role expectations-experiences discrepancy and alliance. It might be harder to form a good alliance to several members in a group. Hence, initial discussion about group rules and group climate are important.

As described above, the therapy groups in Study IV soon became very important to the members who regularly came to the sessions, and these members experienced the continuous decimation of the group negatively. Procedures that can prevent dropout and help patients prepare for group therapy become essential.

In affect focused experiential psychotherapy, a good working relationship between patient and therapist is essential. A strong emotional bond (Bordin, 1979) will support exploration of the patient's internal experiences and expression of affect. When the patient feels accepted and safe and in agreement with therapist on task and goal, the intense work can 
begin (Greenberg \& Safran, 1989). The working alliance was not measured in Study III but the course of the three therapies evidently exposed differences in use of experiential techniques and to what extent the patient's needs and wants based on emotional experiencing could extend out to patients' everyday life. Degree of self-critique and attachment related difficulties may account for the differences.

\section{Expectations and experiences of therapy}

In Study I both Internal Orientation and External Orientation on the expectancy measure PEX1 had high average ratings, a result indicating that patients both want to be able to reflect on their inner processes and carry out practical work on changes in daily life. SUD patients thus expect therapy to be concrete and practically oriented around their problems, something that especially psychodynamic therapists should be aware of. Using concrete techniques to work with the patient's problem is not at odds with a psychodynamic theoretical base regarding origin and development of these problems. Patients' experience of their therapies does indicate that there is a substantial element of practical problem focus in the therapies, which in Study I are mainly with a psychodynamic focus. APT is an example of how concrete techniques of both experiential and cognitive behavioural origins are integrated in dynamic psychotherapy. In Study III the three patients experienced therapy as more focused on expressive, emotionally charged material and less on practically task-oriented material compared to their expectations. The result confirms that the crucial experiential part of APT was not fully elaborated on in the rationale prior to therapy.

The finding in Study I that the Defensiveness scale in PEX-S predicted low retention indicates that the instrument can detect patients who are at risk for dropout. Using the PEX at the beginning of therapy offers a chance to survey defensiveness tendencies and for the therapist and patient to discuss these issues. When patients' expectations are characterized by defensiveness prior to therapy, this can indicate the need to thoroughly examine possible fears concerning therapy or whether psychotherapy is the most suitable action at this stage of time.

\section{Preparing patients for therapy}

Study I and IV evidently display the challenge psychotherapists in substance use care face in helping patients stay in treatment. Dropout rates for SUD patients in treatment have been estimated to be $30 \%$, but for patients with comorbid psychiatric diagnosis the percentage is higher (Dutra et al., 2008). Perhaps a preparation phase where the specific therapist-patient dyad meets 
and discusses the therapy rationale and treatment expectations can be of help. This phase could provide an opportunity for both patient and therapist to negotiate and modify their approach to create a better fit.

In short-term experiential psychotherapy the rationale for treatment is important to describe and discuss at the start of therapy. The experiential focus may be anxiety provoking and the therapist needs to elaborate on the treatment method of exposure to affects and simultaneous anxiety regulation. Also, it is crucial to stress the collaboration between patient and therapist in the patient's process for change. Experiences from Study IV reveal that there is a need for more extensive preparation prior to inclusion.

To prevent dropout and prepare patients for group therapy, a discussion of differences in expectations between group participants and fears about treatment might be a way of strengthening the alliance and improving the likelihood of a good outcome. In affect-focused group therapy there is a potent exposure to self and other issues, and experiencing and expressing emotions to a group may elicit more anxiety than in individual APT. The therapists' reassurance of their responsibility for guiding the process is crucial.

\section{Motivation}

If affects, as Tomkin's theorizes, are biological mechanisms that trigger action to make us aware of what is important in our lives, one can understand their great importance in psychotherapy as well. Affects thus offer an understanding of motivation. In APT the patient's motivation for therapy is thought to be the sensation that experiencing and expressing emotions is fulfilling and gives relief. One of the items in ATOS that measures important treatment objectives in APT is motivation, defined as to what extent the patient wants to give up the maladaptive or defensive behaviour (McCullough et al., 2011). The patient needs to experience that the primary gain of emotion expression is greater than the secondary gain of avoidance. Tomkins' notion that affects is the focal point of motivation stood in contrast with the most common psychological theories on human behaviour, the cognitive, behaviouristic and psychoanalytic perspectives (Tomkins, 1981). Experiential orientations of psychotherapy provide this approach.

\section{Methodological aspects}

\section{Strengths}

Study I in this thesis had a naturalistic design. Study III and IV collected data in a regular clinical setting, i.e. at the Stockholm Center for Dependency 
Disorders, a large public treatment facility, where patients seek help for excessive alcohol and drug use. This strengthens the external validity of the studies (Kazdin, 2003). In Study I different therapists conducted the treatments as they normally do in their routine practice. Patients' length of sobriety varied and also if and to what extent they had comorbid diagnoses. Patients' preference for type of treatment, but also clinical judgement on behalf of the doctor's referral, decided what treatment format the patients received. Length of treatment varied and therapists were allowed to adjust treatment to fit the patient. In Study III fidelity to the treatment manual was checked through video recordings of every therapy session that were viewed weekly by an experienced peer APT therapist/teacher.

In Study III a nonconcurrent multiple baseline design was chosen because APT is a novel treatment for the patient group and thus the design offers a cost-effective methodology when trying out a new treatment for the purpose of providing valuable information for further adjusting the treatment to the patient group. Also, an experimental case design is one method recommended in the evidence-based treatment movement (Chambless \& Hollon, 1998). With a multiple baseline design, it is possible to identify individual differences/variations in treatment-related symptom change. With the small number of patients in Study III it was possible to examine the three patients' therapy processes in depth and relate the findings to the many measuring points that the multiple design offered.

Study IV had an open design with multiple data points in order to increase the opportunity for the patients to become their own controls, similar to single case design studies. Unfortunately, due to attrition, there were fewer available data points than planned.

\section{Limitations}

In contrast to the heightened external validity which studies in regular clinical practice offer, the internal validity was weaker. There were no demands for manual-based treatment and no controls of fidelity to treatment in Study I and IV. In Study I different therapists conducted the treatments; hence therapist effects cannot be ruled out.

Study III used an experimental design, which could have been better prepared. In a multiple baseline design, the minimum sample size is three patients. One out of the three patients included ceased drinking before the start of baseline measurements, thus change related to therapy could not be measured for this patient. Furthermore, the baseline could have been longer to obtain further stability in drinking patterns before treatment commenced. Because of the small sample size, female patients were chosen to obtain more 
homogeneity among the patients. Hence, little is known whether the results could be generalized to men.

A limitation in regard to the psychometric evaluation of the affect phobia test in Study II is limited variation in the samples. Additional clinical sample groups, such as patients with SUD, personality disorder or other severe psychiatric disorders as well as normal sample groups with greater variation in relation to age and occupation would have been preferable. The validity of the test was studied through factor structure and discriminative validity. The test could also have been compared with another measure to assess the criterion validity, e.g. with a test measuring emotional avoidance. Control groups, e.g. a waiting list for Study I and comparisons with other group treatment for Study IV, could have strengthened the studies further.

The fact the primary collection of data is supported by self-report instruments may be a limitation in the studies, since the results are accurate only to the degree that the participants understood the instruments and answered them honestly. Furthermore, even if patients responded to the questionnaires truthfully and correct, the answers do not automatically translate into everyday life activity. Thus, change in answers across therapy cannot automatically be interpreted as real change in daily life, although the measures are standardized (Kazdin, 2008). Continuous biomarkers of alcohol and drug use during treatment would have increased the credibility of patients' self-reports on substance use during treatment and at follow up.

\section{Participation Attrition/Dropout}

The study limitations in the clinical studies mainly concern the small study sample and the dropout rate, which reduces the possibility of generalizing the results. The high attrition rates increase the risk that the patients providing data are not representative of the whole patient sample at the beginning of treatment. If only patients who are satisfied with therapy contribute data, valuable information will be lost. The small sample sizes give the studies low statistical power, which elevates the risk for type 2 errors, making the nonsignificant results difficult to interpret.

This also concerns the multiple data points in Study IV. It was not possible to analyse the baseline period since some of the patients did not answer the weekly phone calls.

\section{Concluding thoughts}

\section{Clinical implications}

As a result of this thesis, the first description of the psychometric properties of the Affect Phobia Test was conducted. The test was developed as a 
screening instrument to estimate fear of affects and use of adaptive affective functioning, and the psychometric evaluation showed that the test can discriminate between individuals who seek psychological help and those who do not and that the empirical cut-off for adaptive affective functioning should be set to $>72$ points. The test is currently translated into three languages (Swedish, Norwegian and Chinese) and the validation of the Swedish version will facilitate future validation in other languages.

The empirical cut-off for adaptive affective functioning can be used in screening for affect phobia prior to treatment. The seven affective domains should not be treated as subscales. Hence the test screens for adaptive affective functioning as a whole. Furthermore, Study III and IV in the thesis provided preliminary results that the test may be used as an outcome measure detecting change in relation to treatment, but further investigations on bigger patient samples are needed for conclusive evidence to be drawn.

This thesis suggests that psychotherapy for patients with SUD and problematic affective avoidance is feasible and that patients can benefit from APT, conducted individually and in a group format.

In individual psychodynamic therapy it traditionally has been the practice to have a longer period of abstinence from alcohol (3-6 months) before the start of therapy. This study demonstrates that APT treatment for patients with mild to moderate alcohol use disorder and affect phobia can begin without a prolonged period of abstinence from alcohol. In the current study, an inclusion criterion was seven sober days preceding the baseline measurement. In retrospect, this requirement was not needed. Clinically, this requirement will hinder patients from entering psychotherapy, when instead treatment should be easily accessible. As an alternative, a biological marker can ensure that the patient does not have an extreme daily consumption of alcohol that might impede the therapy process. Thus, APT treatment could function in the same field of application as MI and RP, and referrals to APT treatment can be made as a first-line treatment. To be able to work more elaborately with defences, affect experiencing, and affect expression for the individual patient, flexibility regarding length of treatment is necessary.

An APT group format was developed in Study IV. Patients with ADHD lack self-regulation capacity related to attention, hyperactivity/ impulsivity and emotion regulation. The dysfunction creates problems related to self and to relations with others, but treatments focusing on the latter are scarce. Hopefully, this treatment approach can fill the gap.

A personal reflection from working therapeutically in substance use dependency care for 13 years is that the therapist can easily develop high tolerance for the dysfunctional aspects of the patients' behaviour, e.g. in regard to attrition. The therapists themselves need to be aware and preventive of such a development. They must demand respect for other group members 
as well as for the their own engagement and effort in conducting the treatment. Self regulation abilities develop in relation to caregivers early in life and when the adult deficient patient comes to therapy one of the therapist's tasks will be to aid in building this capacity, not only soothe the patient's wounds. In retrospect, the patients' reoccurring failure to come into sessions in group therapy could have been utilized in relation to self-other treatment objectives and to adaptive and maladaptive shame. Interviews with patients with SUD have revealed that one reason not to re-enter treatment after dropping out relates to feelings of shame (Nordfjaern et al., 2010).

One clinical implication of the findings in Study I is the potential benefit of therapist and patient discussing treatment expectations at the onset of therapy. In targeting expectancies, potential discrepancies between patient and therapist will be made visible and thus possible to examine together. This approach emphasizes the importance of collaboration and of a joint commitment to therapy and to how the psychotherapy should be conducted.

In the APT manual SUD is considered as a contraindication for therapy. Nevertheless, the disorder is diverse, and in my own clinical practice it is evident that there are groups of patients with AUD that primarily suffer from comorbid conditions, e.g., anxiety and depression. APT helps decrease these symptoms, lessen self-critique and increase adaptive affective functioning. When this happens, alcohol misuse is no longer an issue, either because the patient drinks controllably or has decided to keep absolute abstinence as a measure of self-care. However, since change in brain function related to AUD is intimately connected to emotion regulation abilities, the assessment of severity of the disorder is crucial for determining if APT constitutes a possible treatment choice. Assessment on this note is crucial for AUD patients, since therapy initially will trigger defensive/avoidant behaviour, i.e. alcohol use. Furthermore, self-critique, guilt and shame proneness can elicit substance use behaviour, which makes assessment before initiating therapy essential. High levels of self-critique and low levels of self-compassion are not an impediment for conducting APT but will call for longer treatment periods and is therefore important to acknowledge in the assessment. Before deciding on therapy the Self-compassion scale (SCS) may be used as a screening instrument. Another possibility to ensure safety in conducting APT in dependency care is to continuously screen patients for substance use with biological markers.

\section{Future directions}

The affect phobia test's potential as an evaluation instrument for affect focused psychotherapy is yet to be tested on a grand scale, and future clinical outcome studies with larger sample sizes can explore whether the test is 
sensitive to change and has potential as an outcome measure. Future psychometric evaluative studies need to examine larger patient samples and different clinical and non-clinical groups. Extended questions, e.g. five questions in each of the test's seven affective domains, can give valuable information on a possible factor structure of seven subscales. It would also be interesting to investigate the test's criterion validity with respect to other emotional concepts and measurements, especially on emotional avoidance, a concept closely linked to affect phobia. Also, comparisons with closely related measures of emotion dysregulation and avoidance would be valuable. For example, the Emotional Processing Scale (EPS-25) (Baker et al., 2010) that was used to assess emotional processing deficits and the process of emotional change in Johansson et al.'s study (2013) on Internet delivered APT based treatment. Further research could examine therapists' capacity for adaptive affective functioning. When working with affect focused therapy it is crucial to be aware of one's own affect phobias.

The quest for greater sample size can be raised in relation to all studies in the thesis. Since all the treatment studies presented may be regarded as pilot studies, future research should be concentrated on randomized controlled clinical trials with larger patient samples and an alternative treatment method as a control condition in individual and group therapy for the comorbid patient groups examined in this thesis. Since comorbidity increases the likelihood for dropout and aggravates symptomatology, a suggestion is to include patients diagnosed solely with SUD, preferably AUD. Such a design would extend the knowledge of whether APT can be used as a first line treatment for SUD. In line with this purpose, a suggestion is that inclusion in treatment commences without the inclusion criteria of a period of total abstinence. There is a need for several different treatment options for AUD due to the diversity of the symptomatology and progression of the disorder.

Data from nine semi-structured interviews with patients who participated in APT group treatment has been collected. The interviewer asked questions on patients' experiences of group treatment and whether the treatment leads to change (Elliot, 1999). These data will be analysed in a future study. Further research opportunities lie in conducting process studies on the videorecordings of the therapies in Study III, for instance using ATOS as scoring instruments.

\section{Conclusion}

The Affect Phobia Test shows satisfactory psychometric properties for the total score but not for some of the test's affective domains. The test can discriminate between individuals who seek help for psychological problems and those who do not and as such is a useful screening instrument for detecting emotional difficulties related to psychological malfunction. 
The development of APT as a group intervention and short-term APT as a first line treatment for patients with mild to moderate AUD and affect phobia/emotional avoidance are feasible and promising treatments for treating aspects of malfunction in the SUD population. The thesis did not provide conclusive answers on the association between substance uses and affect phobia/emotional avoidance or whether the treatment objectives could help in reducing substance use. However, the studies did indicate that APT is a possible psychotherapy for the patient groups and that treatment objectives of increasing adaptive affective functioning and enhancing self-compassion were reached for patients who followed through the treatment.

Since functional disability and suffering is high in the patient groups investigated in this thesis, preparation prior to treatment, longer treatment periods and additional adaptation of the treatment model to the specific SUD/SUD-comorbidity population may be needed. Nonetheless, further exploration of the effectiveness of affects focused therapy for SUD may provide valuable complements to today's treatment options. The patient group needs help in alleviating psychiatric symptoms, increasing selfregulation and strengthening their own capacity to create richer and easier everyday life. For these goals, a combination of social, psychotherapeutic, and pharmacological interventions are necessary.

The goal of APT is to restructure and reset the affective motivational system to normal. Thus, APT uses affect theory, the notion of a universally and inherently given motivational system that plays a crucial role in human life, and attempts to integrate it into a clinically manifested therapeutic methodology. Since emotions have a great influence on human life in general and play an important role in motivating and guiding us through life and in our relationships, the ambition to mend and refine the affect system is meaningful.

Regardless of psychotherapeutic orientation and how the function of emotions are understood, working experientially with emotions in psychotherapy and linking emotion to cognitive understanding will be beneficial tools in striving for change.

In conducting psychotherapy with patients with multiple psychiatric problems and dysfunctional behaviours, action must be taken to help patients stay in treatment. 


\section{Acknowledgements in Swedish}

Först av allt vill jag rikta ett stort tack till Stefan Borg, f.d. verksamhetschef på Beroendecentrum Stockholm som gav mig möjlighet att starta mina doktorandstudier och till Johan Franck, nuvarande verksamhetschef, som har möjliggjort dess fortsättning.

Björn Philips, min huvudhandledare. Du har med varsam hand lotsat mig in i psykoterapiforskningens värld och fått mig att känna mig hemma där. Du är klok, skarp, lugn och hjälpsam och har generöst gett av din tid, vilket jag har förstått inte alltid är fallet $i$ handledarbranchen. Så blir du också en rollmodell för mig i mina nuvarande och framtida handledaruppdrag. Med en sådan perfekt avvägning har du släppt på tyglarna och låtit mig ta mer och mer ansvar. Tack också för alla stimulerande och roliga samtal.

Peter Wennberg, min bihandledare. Tillsammans med dig blir statistik förunderligt lätt fast det ju inte är det och jag är tacksam för hur frikostigt du har gett av din kunskap och snabba hjärna. Tack för alla stimulerande och innerliga samtal. Du är en av de vänligaste personer jag mött i mitt yrkesliv.

Men Björn och Peter, jag vill också tacka er gemensamt för vi har varit ett sådant ypperligt team tillsammans. För mig finns inga bättre, tryggare, längre eller ens roligare handledare att hänga ihop med. Tack för all kunskap, allt stöd och alla skratt.

Rolf Holmqvist. Min bihandledare vill jag tacka för att du ser möjligheter och har erbjudit hjälp och snabba handhavanden när jag som bäst behövt det.

Lena Harland. Min närmaste chef under många år. Tack för stöd och intresse.

Maija Konstenius. Min nuvarande chef, som en gång i tiden var den första kollega jag mötte på Beroendecentrum och som så enkelt förde mig in $\mathrm{i}$ händelsernas centrum. Du har varit en god kollega och vän ända sedan dess.

Dilya Hådell. Under så många år nu har du varit min psykologkollega $\mathrm{i}$ rummet bredvid. Du kanske inte vet det, Dilya, men du har många Carl Rogerianska kvaliteter.

Mina forskarkollegor $i$ Linköping. Tack för intressanta och roliga samtal när vi mötts och för trevligt umgänge på konferenser. 
Lene Berggraf. Tack för stöd och lärande i studie III.

Kristin. Thank you for further deepening my understanding of Affect Phobia Therapy. I hope to continue the never-ending learning process together with you.

Barbro Lindhe. Min psykoterapikollega i studie IV. Vårt samarbete och våra samtal värderar jag högt. Du var också en av dem som allra bäst kunde visa att du förstod min smärta och du omfamnade sorgen så enkelt, vilket gjorde den betydligt lättare att bära. Tack!

Tali. You are the kindest, wisest and most modest cousin ever. You show up when I need you the most and with you and I, there is never anything in between that hurt. I cherish our differences and similarities. Thank you for reading study II so meticulously.

Lennart. Tack för all den kärlek du gav mig och för att du lämnade mig en sista ovärderlig gåva: erfarenheten av ren sorg, den slags sorg som helar.

Min stora familj. Tack för att ni bara finns där hela tiden. Ni är som en bassäng att doppa fötterna i, simma omkring i med lugna simtag eller dyka ner i, allt efter behag. Jag är lyckligt lottad som har er. Men ni är ju så många! Det går inte att tacka er en och en. Det får bli mamma och pappa. Jag har alltid tänkt att ni är så olika, men så är det ju inte. Ni är båda generösa, förändringsbenägna och intellektuellt stimulerande att samtala med. Tre egenskaper som jag värderar högt. Hur känns det egentligen att vara älskad från start och framåt? Jag vet inte, men jag tror att det är så jag känner. Tack också mamma, för den allra sista genomläsningen som räddade mig från många errata.

Mina barn. Storm, Isolde, Nanna och Idun. Att ha er myllrande runt omkring mig är underbart. Ni tåliga små människor som visar uppskattning för det lilla och utan att blinka tar emot det stora. Tack för att ni i praktiken lär mig att tillräckligt bra är bra nog. Ni är min rikedom.

Avslutningsvis och allra främst vill jag tacka mina patienter. Ni är mina allra bästa läromästare och när jag får tillåtelse att komma nära blir jag så lycklig. $\mathrm{Du}$ som läser denna text vet att jag håller dig och vårt gemensamma arbete alldeles bredvid mitt hjärta. 


\section{References}

Able, S. L., Johnston, J. A., Adler, L. A., \& Swindle, R. W. (2007).

Functional and psychosocial impairment in adults with undiagnosed ADHD. Psychological Medicine, 37, 97-107. http://doi.org/10.1017/S0033291706008713

Alcaro, A., \& Panksepp, J. (2011). The seeking mind: primal neuro-affective substrates for appetitive incentive states and their pathological dynamics in addictions and depression. Neuroscience and Biobehavioral Reviews, 35, 1805-1820. http://doi.org/10.1016/j.neubiorev.2011.03.002

American Psychiatric Association. (1994). Diagnostic and Statistical Manual of Mental Disorder. (4th ed.). Washington DC: The American Psychiatric Association.

American Psychiatric Association. (2013). Diagnostic and Statistical Manual of Mental Disorders (5th ed.). Washington DC: American Psychiatric Association. http://doi.org/10.1176/appi.books.9780890425596

Attkisson, C., \& Greenfield, T. (n.d.). Client Satisfaction Questionnaire-8 and Service Satisfaction Scale-30.

Aurora, P., \& Klanecky, A. (2016). Drinking motives mediate emotion regulation difficulties and problem drinking in college students. The American Journal of Drug and Alcohol Abuse, 1-10. http://doi.org/10.3109/00952990.2015.1133633

Babor, T. F. (1992). Types of Alcoholics, I. Archives of General Psychiatry, 49, 599. http://doi.org/10.1001/archpsyc.1992.01820080007002

Babor, T. F., \& Caetano, R. (2006). Subtypes of substance dependence and abuse: implications for diagnostic classification and empirical research. Addiction , 101, 104-10. http://doi.org/10.1111/j.13600443.2006.01595.x

Baker, R., Thomas, S., Thomas, P. W., Gower, P., Santonastaso, M., \& Whittlesea, A. (2010). The Emotional Processing Scale: scale refinement and abridgement (EPS-25). Journal of Psychosomatic Research, 68, 83-8. http://doi.org/10.1016/j.jpsychores.2009.07.007

Barkley, R. A., Anastopoulos, A. D., Guevremont, D. C., \& Fletcher, K. E. (1991). Adolescents with ADHD: patterns of behavioral adjustment, academic functioning, and treatment utilization. Journal of the American Academy of Child and Adolescent Psychiatry, 30(5), 752-61. Retrieved from http://www.ncbi.nlm.nih.gov/pubmed/1938790

Barkley, R. A., \& Murphy, K. R. (2010). Impairment in occupational functioning and adult ADHD: the predictive utility of executive function (EF) ratings versus EF tests. Archives of Clinical Neuropsychology: The Official Journal of the National Academy of 
Neuropsychologists, 25, 157-73. http://doi.org/10.1093/arclin/acq014

Barrett Feldman, L. (2017). The theory of constructed emotion: an active inference account of interoception and categorization. Social Cognitive and Affective Neuroscience. http://doi.org/10.1093/scan/nsx060

Berking, M., Margraf, M., Ebert, D., Wupperman, P., Hofmann, S. G., \& Junghanns, K. (2011). Deficits in emotion-regulation skills predict alcohol use during and after cognitive-behavioral therapy for alcohol dependence. Journal of Consulting and Clinical Psychology, 79, 307318. http://doi.org/10.1037/a0023421

Berman, A., Bergman, H., Palmstierna, T., \& Schlyter, F. (2005). Evaluation of the drug use disorders identification test (DUDIT) in criminal justice and detoxification settings and in a Swedish population sample.

European Addiction Research, 11(1), 22-31.

http://doi.org/10.1159/000081413

Berman, A., Wennberg, P., \& Källmén, H. (2012). AUDIT and DUDIT identifying problematic use of alcohol and drugs. Stockholm: Gothia förlag.

Bizzarri, J. V., Rucci, P., Sbrana, A., Gonnelli, C., Massei, G. J., Ravani, L., ... Cassano, G. B. (2007). Reasons for substance use and vulnerability factors in patients with substance use disorder and anxiety or mood disorders. Addictive Behaviors, 32(2), 384-391. http://doi.org/10.1016/j.addbeh.2006.04.005

Bohart, A. C., \& Greaves Wade, A. (2013). The client in psychotherapy. In M. J. Lambert (Ed.), Bergin and Garfield's handbook of psychotherapy and behavior change (6th ed., pp. 219-257). New Jersey: John Wiley \& Son, Inc.

Bordin, E. S. (1979). The generalizability of the psychoanalytic concept of the working alliance. Psychotherapy: Theory, Research \& Practice, 16, 252-260. http://doi.org/10.1037/h0085885

Boschloo, L., Vogelzangs, N., Smit, J. H., van den Brink, W., Veltman, D. J., Beekman, A. T. F., \& Penninx, B. W. J. H. (2011). Comorbidity and risk indicators for alcohol use disorders among persons with anxiety and/or depressive disorders: findings from the Netherlands Study of Depression and Anxiety (NESDA). Journal of Affective Disorders, 131, 233-42. http://doi.org/10.1016/j.jad.2010.12.014

Bowlby, J. (1988). A Secure Base. Clinical Applications of Attachment Theory. Psychology Press.

Brown, S., \& Yalom, I. (1977). Interational group therapy with alcoholics. Journal of Studies on Alcohol, 38(3), 426-56. Retrieved from http://www.ncbi.nlm.nih.gov/pubmed/859331

Brown, T. E. (1996). Brown attention deficit disorder scales for adolescents and adults. San Antonio: The Psychological Corporation. 
Brådvik, L., Mattisson, C., Bogren, M., \& Nettelbladt, P. (2010). Mental disorders in suicide and undetermined death in the Lundby Study. The contribution of severe depression and alcohol dependence. Archives of Suicide Research: Official Journal of the International Academy for Suicide Research, 14, 266-75. http://doi.org/10.1080/13811118.2010.494146

Burlingame, G. M., McClendon, D. T., \& Alonso, J. (2011). Cohesion in group therapy. In J. C. Norcross (Ed.), Psychotherapy relationships that work: Evidence-based responsiveness (2nd ed., pp. 110-131). New York: Oxford University Press Inc.

Cacioppo, J., Amaral, D., Blanchard, J., Cameron, J., Sue Carter, C., Crews, D., ... Quinn, K. (2007). Social neuroscience: Progress and implications for mental health. Perspectives on Psychological Science, 2, 99-123. http://doi.org/10.1111/j.1745-6916.2007.00032.x

CAN- The Swedish council for information on alcohol and other drugs. (2010). Drogutveckling i Sverige 2010. Rapport 125. Stockholm. Retrieved from http://www.can.se/contentassets/97d77ab4b84540179a16e08ac177efd8/ can-rapportserie-125-drogutvecklingen-i-sverige-2010.pdf

CAN The Swedish council for information on alcohol and other drugs. (2017). Drug trends in Sweden 2017. CAN report 163. Stockholm. Retrieved from http://www.can.se/contentassets/f07e89e00e1747e19e410262be17d954/ drug-trends-in-sweden-2017.pdf

Chambless, D. L., \& Hollon, S. D. (1998). Defining empirically supported therapies. Journal of Consulting and Clinical Psychology, 66, 7-18. http://doi.org/10.1037/0022-006X.66.1.7

Clarkin, D. F., \& Levy, K. N. (2004). The influence of client variables on psychotherapy. In M. J. Lambert (Ed.), Bergin and Garfield's handbook of psychotherapy and behavior change (5th ed., pp. 194-226). New York: John Wiley \& Sons, Inc.

Clinton, D. (2001). Expectations and experiences of treatment in eating disorders. Eating Disorders, 9, 361-371. http://doi.org/10.1080/106402601753454921

Clinton, D., \& Sandell, R. (2003). PEX-psychotherapy expectations and experience questionnaire. Unpublished manuscript.

Cloninger, C. (1981). Inheritance of Alcohol Abuse. Archives of General Psychiatry, 38, 861. http://doi.org/10.1001/archpsyc.1981.01780330019001

Cohen, P., Chen, H., Crawford, T. N., Brook, J. S., \& Gordon, K. (2007). Personality disorders in early adolescence and the development of later substance use disorders in the general population. Drug and Alcohol 
Dependence, 88 , S71-S84.

http://doi.org/10.1016/j.drugalcdep.2006.12.012

Constantino, M. J., Arnkoff, D. B., Glass, C. R., Ametrano, R. M., \& Smith, J. Z. (2011). Expectations. Journal of Clinical Psychology, 67, 184-92. http://doi.org/10.1002/jclp.20754

Cooney, N. L., Kadden, R. M., Litt, M. D., \& Getter, H. (1991). Matching alcoholics to coping skills or interactional therapies: Two-year followup results. Journal of Consulting and Clinical Psychology, 59(4), 598601. Retrieved from http://ovidsp.tx.ovid.com.proxy.kib.ki.se

Cooper, M. (1994). Motivations for alcohol use among adolescents: Development and validation of a four-factor model. Psychological Assessment, 6(2), 117-128. Retrieved from http://ww.org.e.bibl.liu.se

Cooper, M., Frone, M., Russell, M., \& Mudar, P. (1995). Drinking to regulate positive and negative emotions: a motivational model of alcohol use. Journal of Personality and Social Psychology, 69(5), 990-1005. Retrieved from http://www.ncbi.nlm.nih.gov/pubmed/7473043

Corbisiero, S., Stieglitz, R.-D., Retz, W., \& Rösler, M. (2013). Is emotional dysregulation part of the psychopathology of ADHD in adults? Attention Deficit and Hyperactivity Disorders, 5, 83-92. http://doi.org/10.1007/s12402-012-0097-z

Crits-Christoph, P., Johnson, J. E., Connolly Gibbons, M. B., \& Mukherjee, D. (2013). Process-outcome research. In M. J. Lambert (Ed.), Bergin and Garfield's handbook of psychotherapy and behavior change (6th ed., pp. 298-340). New Jersey: John Wiley \& Sons, Inc.

Darwin, C. (1872). The expression of the emotions in man and animals (3rd ed.). New York: Oxford University Press.

Davanloo, H. (1980). Short-term dynamic psychotherapy. New York: Jason Aronson.

Davis, K. L., \& Panksepp, J. (2011). The brain's emotional foundations of human personality and the affective neuroscience personality scales. Neuroscience and Biobehavioral Reviews, 35, 1946-1958. http://doi.org/10.1016/j.neubiorev.2011.04.004

Dearing, R. L., Stuewig, J., \& Tangney, J. P. (2005). On the importance of distinguishing shame from guilt: Relations to problematic alcohol and drug use. Addictive Behaviors, 30, 1392-1404. http://doi.org/10.1016/j.addbeh.2005.02.002

Diener, M. J., Hilsenroth, M. J., \& Weinberger, J. (2007). Therapist Affect Focus and Patient Outcomes in Psychodynamic Psychotherapy: A Meta-Analysis. American Journal of Psychiatry, 164, 936-941. http://doi.org/10.1176/ajp.2007.164.6.936

Duckro, P., Beal, D., \& George, C. (1979). Research on the effects of disconfirmed client role expectations in psychotherapy: A critical 
review. Psychological Bulletin, 86(2), 260-75. Retrieved from http://www.ncbi.nlm.nih.gov/pubmed/382222

Dutra, L., Stathopoulou, G., Basden, S. L., Leyro, T. M., Powers, M. B., \& Otto, M. W. (2008). A Meta-Analytic Review of Psychosocial Interventions for Substance Use Disorders. American Journal of Psychiatry, 165, 179-187. http://doi.org/10.1176/appi.ajp.2007.06111851

Dvorak, R. D., Sargent, E. M., Kilwein, T. M., Stevenson, B. L., Kuvaas, N. J., \& Williams, T. J. (2014). Alcohol use and alcohol-related consequences: associations with emotion regulation difficulties. The American Journal of Drug and Alcohol Abuse, 40, 125-30. http://doi.org/10.3109/00952990.2013.877920

Ekman, P., \& Cordaro, D. (2011). What is meant by calling emotions basic. Emotion Review, 3, 364-370. http://doi.org/10.1177/1754073911410740

Elliot, R. (1999). Client Change Interview Protocol. Network for Research on Experiential Psychotherapies. Retrieved from http://experientialresearchers.org/instruments/elliott/changei.pdf

Elliott, R., Bohart, A. C., Watson, J. C., \& Greenberg, L. S. (2011). Empathy. Psychotherapy (Chicago, Ill.), 48, 43-9. http://doi.org/10.1037/a0022187

Emilsson, B., Gudjonsson, G., Sigurdsson, J. F., Baldursson, G., Einarsson, E., Olafsdottir, H., \& Young, S. (2011). Cognitive behaviour therapy in medication-treated adults with ADHD and persistent symptoms: a randomized controlled trial. BMC Psychiatry, 11, 116. http://doi.org/10.1186/1471-244X-11-116

Fals-Stewart, W., O'Farrell, T. J., Freitas, T. T., McFarlin, S. K., \& Rutigliano, P. (2000). The timeline followback reports of psychoactive substance use by drug-abusing patients: Psychometric properties. Journal of Consulting and Clinical Psychology, 68(1), 134-44. Retrieved from http://www.ncbi.nlm.nih.gov/pubmed/10710848

Flannery, B. A., Volpicelli, J. R., \& Pettinati, H. M. (1999). Psychometric properties of the penn alcohol craving csale. Alcoholism: Clinical and Experimental Research, 23, 1289-1295. http://doi.org/10.1111/j.15300277.1999.tb04349.x

Fleischmann, A., \& Fleischmann, R. H. (2012). Advantages of an ADHD Diagnosis in Adulthood: Evidence From Online Narratives. Qualitative Health Research, 22, 1486-1496. http://doi.org/10.1177/1049732312457468

Fosha, D. (2000). The transforming power of affect: A model for accelerated change. New York: Basic Books.

Fosha, D., Siegel, D. J., \& Solomon, M. (Eds.). (2009). The healing power of 
emotion. Affective neuroscience, development \& clinical practice. New York: WW Norton Co.

Frankl, M., Philips, B., Berggraf, L., Ulvenes, P., Johansson, R., \&

Wennberg, P. (2016). Psychometric properties of the Affect Phobia

Test. Scandinavian Journal of Psychology, 57, 482-488.

http://doi.org/10.1111/sjop.12308

Freud, S. (1977). Inhibitions, symptoms and anxiety. New York: WW Norton Co. (Original work published 1926).

Greenberg, L. (1986). Change process research. Journal of Consulting and Clinical Psychology, 54(1), 4-9. Retrieved from http://www.ncbi.nlm.nih.gov/pubmed/3958300

Greenberg, L. (2012). Emotions, the great captains of our lives: their role in the process of change in psychotherapy. The American Psychologist, 67, 697-707. http://doi.org/10.1037/a0029858

Greenberg, L., \& Safran, J. (1987). Emotion in psychotherapy: affect, cognition, and the process of change. New York: Guilford Press.

Greenberg, L., \& Safran, J. (1989). Emotion in psychotherapy. The American Psychologist, 44(1), 19-29. Retrieved from http://ovidsp.tx.ovid.com.proxy.kib.ki.se

Greenberg, L., \& Watson, J. (1998). Experiential Therapy of Depression: Differential Effects of Client-Centered Relationship Conditions and Process Experiential Interventions. Psychotherapy Research, 8, 210224. http://doi.org/10.1080/10503309812331332317

Gross, J. J. (1998a). Antecedent- and response-focused emotion regulation: Divergent consequences for experience, expression, and physiology. Journal of Personality and Social Psychology, 74(1), 224-37. Retrieved from http://ovidsp.tx.ovid.com.proxy.kib.ki.se

Gross, J. J. (1998b). The Emerging Field of Emotion Regulation: An Integrative Review. Review of General Psychology, 2, 271-299. Retrieved from http://ovidsp.tx.ovid.com.proxy.kib.ki.se

Gross, J. J. (2013). Emotion regulation: taking stock and moving forward. Emotion, 13, 359-65. http://doi.org/10.1037/a0032135

Gross, J. J., \& Barrett Feldman, L. (2013). The emerging field of affective science. Emotion, 13, 997-998. http://doi.org/10.1037/a0034512

Gross, J. J., \& John, O. (2003). Individual differences in two emotion regulation processes: Implications for affect, relationships, and wellbeing. Journal of Personality and Social Psychology, 85, 348-362. http://doi.org/10.1037/0022-3514.85.2.348

Gross, J. J., \& Levenson, R. W. (1997). Hiding feelings: the acute effects of inhibiting negative and positive emotion. Journal of Abnormal Psychology, 106(1), 95-103. Retrieved from http://ovidsp.tx.ovid.com.proxy.kib.ki.se 
Guy, W. (1976). Clinical Global Impressions: In ECDEU Assessment Manual for Psychopharmacology. In National Institute for Mental Health. Library. DHEW Pub.:Rockville.

Halberstadt, A. G., \& Lozada, F. T. (2011). Emotion development in infancy through the lens of culture. Emotion Review, 3, 158-168. http://doi.org/10.1177/1754073910387946

Harold, G. T., Leve, L. D., Barrett, D., Elam, K., Neiderhiser, J. M., Natsuaki, M. N., ... Thapar, A. (2013). Biological and rearing mother influences on child ADHD symptoms: revisiting the developmental interface between nature and nurture. Journal of Child Psychology and Psychiatry, and Allied Disciplines, 54, 1038-46. http://doi.org/10.1111/jcpp.12100

Hayes, S., \& Strosahl, K. (2004). A practical guide to acceptance and commitment therapy. New York: Springer.

Hayes, S., Wilson, K., \& Strosahl, K. (1996). Experiential avoidance and behavioral disorders: A functional dimensional approach to diagnosis and treatment. Journal of Consulting and Clinical Psychology, 64(6), 1152-1168. Retrieved from http://ovidsp.tx.ovid.com.proxy.kib.ki.se

Hesselbrock, V. M., \& Hesselbrock, M. N. (2006). Are there empirically supported and clinically useful subtypes of alcohol dependence? Addiction, 101, 97-103. http://doi.org/10.1111/j.13600443.2006.01596.x

Hirvikoski, T., Waaler, E., Alfredsson, J., Pihlgren, C., Holmström, A., Johnson, A., ... Nordström, A.-L. (2011). Reduced ADHD symptoms in adults with ADHD after structured skills training group: results from a randomized controlled trial. Behaviour Research and Therapy, 49, 17585. http://doi.org/10.1016/j.brat.2011.01.001

Horvath, A. O., Del Re, A. C., Flückiger, C., \& Symonds, D. (2011). Alliance in individual psychotherapy. Psychotherapy, 48, 9-16. http://doi.org/10.1037/a0022186

Iacoviello, B. M., McCarthy, K. S., Barrett, M. S., Rynn, M., Gallop, R., \& Barber, J. P. (2007). Treatment preferences affect the therapeutic alliance: implications for randomized controlled trials. Journal of Consulting and Clinical Psychology, 75, 194-8. http://doi.org/10.1037/0022-006X.75.1.194

Izard, C. E., Woodburn, E. M., Finlon, K. J., Krauthamer-Ewing, E. S., Grossman, S. R., \& Seidenfeld, A. (2011). Emotion knowledge, emotion utilization, and emotion regulation. Emotion Review, 3, 44-52. http://doi.org/10.1177/1754073910380972

Jacobson, N. S., \& Truax, P. (1991). Clinical significance: a statistical approach to defining meaningful change in psychotherapy research. Journal of Consulting and Clinical Pychology, 59(1), 12-19. Retrieved 
from http://ovidsp.tx.ovid.com.proxy.kib.ki.se

Johansson, R., Björklund, M., Hornborg, C., Karlsson, S., Hesser, H., Ljótsson, B., ... Andersson, G. (2013). Affect-focused psychodynamic psychotherapy for depression and anxiety through the Internet: A randomized controlled trial. PeerJ, 1, 102:

http://doi.org/10.7717/peerj.102

Kadden, R. M., Cooney, N. L., Getter, H., \& Litt, M. D. (1989). Matching alcoholics to coping skills or interactional therapies: Posttreatment results. Journal of Consulting and Clinical Psychology, 57(6), 698-704. Retrieved from http://ovidsp.tx.ovid.com.proxy.kib.ki.se

Kadden, R. M., Litt, M. D., Cooney, N. L., Kabela, E., \& Getter, H. (2001). Prospective matching of alcoholic clients to cognitive- behavioral or interactional group therapy. Journal of Studies on Alcohol and Drugs, $62(3), 359$.

Kazdin, A. E. (2003). Research design in clinical psychology (4th ed.). Boston, MA: Allyn \& Bacon.

Kazdin, A. E. (2008). Evidence-based treatment and practice: new opportunities to bridge clinical research and practice, enhance the knowledge base, and improve patient care. The American Psychologist, 63, 146-59. http://doi.org/10.1037/0003-066X.63.3.146

Kessler, R. C., Adler, L., Barkley, R. A., Biederman, J., Conners, C. K., Demler, O., ... Zaslavsky, A. M. (2006). The prevalence and correlates of adult ADHD in the United States: results from the National Comorbidity Survey Replication. The American Journal of Psychiatry, 163, 716-23. http://doi.org/10.1176/appi.ajp.163.4.716

Khantzian, E. J. (1997). The self-medication hypothesis of substance use disorders: a reconsideration and recent applications. Harvard Review of Psychiatry, 4, 231-44. http://doi.org/10.3109/10673229709030550

Khantzian, E. J. (2003). Understanding addictive vulnerability: An evolving psychodynamic perspective. Neuro-Psychoanalysis, 5, 5-21. http://doi.org/http://dx.doi.org/10.1080/15294145.2003.10773403

Khantzian, E. J. (2012). Reflections on treating addictive disorders: a psychodynamic perspective. The American Journal on Addictions / American Academy of Psychiatrists in Alcoholism and Addictions, 21, 274-279. http://doi.org/10.1111/j.1521-0391.2012.00234.x

Knouse, L. E., \& Safren, S. A. (2010). Current status of cognitive behavioral therapy for adult attention-deficit hyperactivity disorder. The Psychiatric Clinics of North America, 33, 497-509. http://doi.org/10.1016/j.psc.2010.04.001

Kohut, H. (1971). The Analysis of the Self: A Systematic Approach to the Psychoanalytic Treatment of Narcissistic Personality Disorders. New York: Internationl Universities Press. 
Kohut, H. (1977). The Restoration of the Self. New York: International Universities Press.

Konstenius, M., Jayaram-Lindström, N., Beck, O., \& Franck, J. (2010). Sustained release methylphenidate for the treatment of ADHD in amphetamine abusers: a pilot study. Drug and Alcohol Dependence, 108, 130-3. http://doi.org/10.1016/j.drugalcdep.2009.11.006

Konstenius, M., Jayaram-Lindström, N., Guterstam, J., Beck, O., Philips, B., \& Franck, J. (2014). Methylphenidate for attention deficit hyperactivity disorder and drug relapse in criminal offenders with substance dependence: a 24-week randomized placebo-controlled trial. Addiction (Abingdon, England), 109, 440-9. http://doi.org/10.1111/add.12369

Koob, G. F., \& Simon, E. J. (2009). The Neurobiology of Addiction: Where We Have Been and Where We Are Going. Journal of Drug Issues, 39(1), 115-132. Retrieved from http://www.ncbi.nlm.nih.gov/pubmed/20622969

Koob, G. F., \& Volkow, N. D. (2010). Neurocircuitry of addiction. Neuropsychopharmacology: Official Publication of the American College of Neuropsychopharmacology, 35, 217-38. http://doi.org/10.1038/npp.2009.110

Koob, G. F., \& Volkow, N. D. (2016). Neurobiology of addiction: a neurocircuitry analysis. The Lancet Psychiatry, 3(8), 760-773. http://doi.org/10.1016/S2215-0366(16)00104-8

Kreibig, S. D. (2010). Autonomic nervous system activity in emotion: a review. Biological Psychology, 84, 394-421. http://doi.org/10.1016/j.biopsycho.2010.03.010

Kuntsche, E., Knibbe, R., Gmel, G., \& Engels, R. (2005). Why do young people drink? A review of drinking motives. Clinical Psychology Review, 25, 841-61. http://doi.org/10.1016/j.cpr.2005.06.002

Lambert, M. J. (2013). The efficacy and effectiveness of psychotherapy. In M. J. Lambert (Ed.), Bergin and Garfield's handbook of psychotherapy and behavior change (6th ed., pp. 169-219). New Jersey: John Wiley \& Sons, Inc.

Lambert, M. J., Burlingame, G. M., Umphress, V., Hansen, N. B., Vermeersch, D. A., Clouse, G. C., \& Yanchar, S. C. (1996). The reliability and validity of the outcome questionnaire. Clinical Psychology \& Psychotherapy, 3, 249-258. http://doi.org/10.1002/(SICI)1099-0879(199612)3:4<249::AIDCPP106>3.0.CO;2-S

LeDoux, J. (2000). Emotion circuits in the brain. Annual Review of Neuroscience, 23, 155-184. http://doi.org/10.1146/annurev.neuro.23.1.155

LeDoux, J. (2012). Rethinking the emotional brain. Neuron, 73, 653-766. 
http://doi.org/10.1016/j.neuron.2012.02.004

Lee, E. B., An, W., Levin, M. E., \& Twohig, M. P. (2015). An initial metaanalysis of Acceptance and Commitment Therapy for treating substance use disorders. Drug and Alcohol Dependence, 155, 1-7.

http://doi.org/10.1016/j.drugalcdep.2015.08.004

Leggio, L., Kenna, G., Fenton, M., Bonenfant, E., \& Swift, R. (2009).

Typologies of alcohol dependence. From Jellinek to genetics and beyond. Neuropsychology Review, 19, 115-129.

http://doi.org/10.1007/s11065-008-9080-z

Levenson, R. W. (2011). Basic emotion questions. Emotion Review, 3, 379386. http://doi.org/10.1177/1754073911410743

Levin, F. R., Evans, S. M., Brooks, D. J., \& Garawi, F. (2007). Treatment of cocaine dependent treatment seekers with adult ADHD: double-blind comparison of methylphenidate and placebo. Drug and Alcohol Dependence, 87, 20-9. http://doi.org/10.1016/j.drugalcdep.2006.07.004

Levin, F. R., Evans, S. M., Brooks, D. J., Kalbag, A. S., Garawi, F., \& Nunes, E. V. (2006). Treatment of methadone-maintained patients with adult ADHD: double-blind comparison of methylphenidate, bupropion and placebo. Drug and Alcohol Dependence, 81, 137-48. http://doi.org/10.1016/j.drugalcdep.2005.06.012

Levin, F. R., Mariani, J. J., Specker, S., Mooney, M., Mahony, A., Brooks, D. J., ... Grabowski, J. (2015). Extended-Release Mixed Amphetamine Salts vs Placebo for Comorbid Adult Attention-Deficit/Hyperactivity Disorder and Cocaine Use Disorder. JAMA Psychiatry, 72, 593. http://doi.org/10.1001/jamapsychiatry.2015.41

Lindgren, A., Barber, J. P., \& Sandahl, C. (2008). Alliance to the group-as-awhole as a predictor of outcome in psychodynamic group therapy.

International Journal of Group Psychotherapy, 58, 163-84. http://doi.org/10.1521/ijgp.2008.58.2.163

Linehan, M. (1993). Cognitive-behavioral treatment of borderline personality disorder. New York: Guilford Press.

Litt, M. D., Babor, T. F., DelBoca, F. K., Kadden, R. M., \& Cooney, N. L. (1992). Types of alcoholics, II. Application of an empirically derived typology to treatment matching. Archives of General Psychiatry, 49(8), 609-14. Retrieved from http://www.ncbi.nlm.nih.gov/pubmed/1322118

Luoma, J. B., Guinther, P., Potter, J., \& Cheslock, M. (2017). ExperiencedBased Versus Scenario-Based Assessments of Shame and Guilt and Their Relationship to Alcohol Consumption and Problems. Substance Use \& Misuse, 1-9. http://doi.org/10.1080/10826084.2017.1305416

Luoma, J. B ., Kohlenberg, B. S., Hayes, S. C., \& Fletcher, L. (2012). Slow and steady wins the race: A randomized clinical trial of acceptance and commitment therapy targeting shame in substance use disorders. 
Journal of Consulting and Clinical Psychology, 80, 43-53. http://doi.org/10.1037/a0026070

Malan, D. (1976). The frontier of brief psychotherapy: an example of the convergence of research and clinical practice. New York: Plenum Press.

Malan, D. (1979). Individual psychotherapy and the science of psychodynamics. Oxford: Butterworth.

Marchant, B. K., Reimherr, F. W., Robison, D., Robison, R. J., \& Wender, P. H. (2013). Psychometric properties of the Wender-Reimherr adult attention deficit disorder scale. Psychological Assessment, 25, 942-50. http://doi.org/10.1037/a0032797

Marlatt, G. A., \& Donovan, D. M. (2005). Relapse prevention: Maintenance strategies in the treatment of addictive behaviors. (2nd ed.). New York: Guilford Press.

McCullough, L., \& Andrews, S. (2001). Assimilative integration: Short-term dynamic psychotherapy for treating affect phobias. Clinical Psychology: Science and Practice, 8, 82-97. http://doi.org/10.1093/clipsy.8.1.23

McCullough, L., Bhatia, M., Ulvenes, P. G., Berggraf, L., \& Osborn, K. (2011). Learning how to rate video-recorded therapy sessions: a practical guide for trainees and advanced clinicians. Psychotherapy, 48, 127-137. http://doi.org/10.1037/a0023131

McCullough, L., Kuhn, N., Andrews, S., Hatch, D., Valen, J., \& Osimo, F. (2003). The reliability of the achievement of therapeutic objectives scale: Five studies. Journal of Brief Psychotherapy, 2, 1-14. Retrieved from http://affectphobiatherapy.com/wp-content/uploads/2013/10/Thereliability-of-ATOS.pdf

McCullough, L., Kuhn, N., Andrews, S., Kaplan, A., Wolf, J., \& Hurley, C. (2003). Treating affect phobia: A manual for short-term dynamic psychotherapy. New York: The Guilford Press.

McCullough Vaillant, L. (1997). Changing character: Short-term anxietyregulating psychotherapy for restructuring defenses, affects, and attachment. New York: Basic Books.

Miller, W. R., \& Rollnick, S. (2002). Motivational interviewing: Preparing people for change (2nd ed.). New York: Guilford Press.

Mongia, M., \& Hechtman, L. (2012). Cognitive behavior therapy for adults with attention-deficit/hyperactivity disorder: a review of recent randomized controlled trials. Current Psychiatry Reports, 14, 561-7. http://doi.org/10.1007/s11920-012-0303-x

Moyers, T. B., \& Miller, W. R. (2013). Is low therapist empathy toxic?

Psychology of Addictive Behaviors, 27, 878-884.

http://doi.org/10.1037/a0030274 
Nathanson, D. L. (2008). Prologue: Affect imagery consciousness. In S. S. Tomkins (Ed.), Affect imagery consciousness: The complete edition. New York: Springer Publishing. Retrieved from http://www.tomkins.org/wp-content/uploads/2014/07/PROLOGUEnathanson.pdf

National Board of Health and Welfare. (2015). Nationella riktlinjer för vård och stöd vid missbruk och beroende - Stöd för styrning och ledning. Retrieved from http://www.socialstyrelsen.se/nationellariktlinjermissbrukochberoende

Neff, K. (2003). The Development and Validation of a Scale to Measure Self-Compassion. Self and Identity, 2, 223-250. http://doi.org/10.1080/15298860309027

Neff, K., \& McGehee, P. (2010). Self-compassion and psychological resilience among adolescents and young adults. Self and Identity, 9, 225-240. http://doi.org/10.1080/15298860902979307

Neff, K., Whittaker, T., \& Karl, A. (2017). Examining the Factor Structure of the Self-Compassion Scale in Four Distinct Populations: Is the Use of a Total Scale Score Justified? Journal of Personality Assessment, 1-12. http://doi.org/10.1080/00223891.2016.1269334

Nogueira, M., Bosch, R., Valero, S., Gómez-Barros, N., Palomar, G., Richarte, V., ... Ramos-Quiroga, J. A. (2014). Early-age clinical and developmental features associated to Substance Use Disorders in Attention-Deficit/Hyperactivity Disorder in Adults. Comprehensive Psychiatry, 55, 639-49. http://doi.org/10.1016/j.comppsych.2013.12.002

Norcross, J. C. (Ed.). (2011). Psychotherapy relationships that work (2nd ed.). New York: NY: Oxford University Press.

Nordfjaern, T., Rundmo, T., \& Hole, R. (2010). Treatment and recovery as perceived by patients with substance addiction. Journal of Psychiatric and Mental Health Nursing, 17, 46-64. http://doi.org/10.1111/j.13652850.2009.01477.x

Norman, G. J., Berntson, G. G., \& Cacioppo, J. T. (2014). Emotion, somatovisceral afference, and autonomic regulation. Emotion Review, 6, 113-123. http://doi.org/10.1177/1754073913512006

Ohlmeier, M. D., Peters, K., Te Wildt, B. T., Zedler, M., Ziegenbein, M., Wiese, B., ... Schneider, U. (2008). Comorbidity of alcohol and substance dependence with attention-deficit/hyperactivity disorder (ADHD). Alcohol and Alcoholism (Oxford, Oxfordshire), 43, 300-4. http://doi.org/10.1093/alcalc/agn014

Orlinsky, D. E., Ronnerstad, M. H., \& Wilutzki, U. (2004). Fifty-years of psychotherapy process-outcome research: Continuity and change. In M. J. Lambert (Ed.), Bergin and Garfield's handbook of psychotherapy and 
behavior change (5th ed., pp. 307-389). New York: Wiley.

Panksepp, J. (2011). What is an emotional feeling? Lessons about affective origins from cross-species neuroscience. Motivation and Emotion, 36, 4-15. http://doi.org/10.1007/s11031-011-9232-y

Panksepp, J. (2012). What is an emotional feeling? Lessons about affective origins from cross-species neuroscience. Motivation and Emotion, 36(1), 4-15. http://doi.org/10.1007/s11031-011-9232-y

Panksepp, J. (2013). Cross-species neuroaffective parsing of primal emotional desires and aversions in mammals. Emotion Review, 5, 235240. http://doi.org/10.1177/1754073913477515

Panksepp, J., \& Watt, D. (2011). What is basic about basic emotions? Lasting lessons from affective neuroscience. Emotion Review, 3, 387-396. http://doi.org/10.1177/1754073911410741

Perls, F., Hefferline, R., \& Goodman, P. (1994). Gestalt Therapy. New Your: Dell. Retrieved from http://www.bokus.com/bok/9780285626652/gestalt-therapy/

Petrakis, I. L., Gonzalez, G., Rosenheck, R., \& Krystal, J. H. (2002). Comorbidity of Alcoholism and Psychiatric Disorders - An overview.

Philipsen, A., Jans, T., Graf, E., Matthies, S., Borel, P., Colla, M., ... Tebartz van Elst, L. (2015). Effects of Group Psychotherapy, Individual Counseling, Methylphenidate, and Placebo in the Treatment of Adult Attention-Deficit/Hyperactivity Disorder. JAMA Psychiatry, 72, 1199210. http://doi.org/10.1001/jamapsychiatry.2015.2146

Safren, S. A., Otto, M. W., Sprich, S., Winett, C. L., Wilens, T. E., \& Biederman, J. (2005). Cognitive-behavioral therapy for ADHD in medication-treated adults with continued symptoms. Behaviour Research and Therapy, 43, 831-42. http://doi.org/10.1016/j.brat.2004.07.001

Sandahl, C., Herlitz, K., \& Ahlin, G. (1998). Time-limited group psychotherapy for moderately alcohol dependent patients. A randomized controlled clinical trial. Psychotherapy Research, 8, 361378. http://doi.org/10.1080/10503309812331332467

Schanche, E., Stiles, T., McCullough, L., Svartberg, M., \& Nielsen, G. (2011). The relationship between activating affects, inhibitory affects, and self-compassion in patients with cluster c personality disorders. Psychotherapy, 48, 293-303. http://doi.org/10.1037/a0022012

Schubiner, H., Saules, K. K., Arfken, C. L., Johanson, C. E., Schuster, C. R., Lockhart, N., ... Pihlgren, E. (2002). Double-blind placebo-controlled trial of methylphenidate in the treatment of adult ADHD patients with comorbid cocaine dependence. Exp Clin Psychopharmacol, 10(3), 286294. Retrieved from http://www.ncbi.nlm.nih.gov/pubmed/12233989

Sharpe, P. C. (2001). Biochemical detection and monitoring of alcohol abuse 
and abstinence. Annals of Clinical Biochemistry, 38, 652-664. http://doi.org/10.1258/0004563011901064

Sifneos, P. E. (1979). Short-Term Dynamic Psychotherapy: Evaluation and Technique. New York: Plenum Press.

Singer, J., \& Fagan, J. (1992). Negative affect, emotional expression and forgetting in young infants. Developmental Psychology, 28(1), 48-57. Retrieved from http://ovidsp.tx.ovid.com.proxy.kib.ki.se

Skirrow, C., \& Asherson, P. (2013). Emotional lability, comorbidity and impairment in adults with attention-deficit hyperactivity disorder. Journal of Affective Disorders, 147, 80-6. http://doi.org/10.1016/j.jad.2012.10.011

Skokauskas, N., McNicholas, F., Masaud, T., \& Frodl, T. (2011). Complementary medicine for children and young people who have attention deficit hyperactivity disorder. Current Opinion in Psychiatry, 24, 291-300. http://doi.org/10.1097/YCO.0b013e32834776bd

Sobell, L. C., \& Sobell, M. B. (1992). Time line follow back. A technique for assessing self-reported alcohol consumption. In R. Litten \& J. Allen (Eds.), Measuring Alcohol Consumption: Psychosocial and Biochemical Methods. (pp. 41-72). New Jersey: Humana Press.

Solanto, M., Marks, D., Wasserstein, J., Mitchell, K., Abikoff, H., Alvir, J., \& Kofman, M. (2010). Efficacy of meta-cognitive therapy for adult ADHD. The American Journal of Psychiatry, 167, 958-68. http://doi.org/10.1176/appi.ajp.2009.09081123

Sonuga-Barke, E. J. S., Brandeis, D., Cortese, S., Daley, D., Ferrin, M., Holtmann, M., ... Sergeant, J. (2013). Nonpharmacological interventions for ADHD: systematic review and meta-analyses of randomized controlled trials of dietary and psychological treatments. The American Journal of Psychiatry, 170, 275-89. http://doi.org/10.1176/appi.ajp.2012.12070991

Stapinski, L. A., Edwards, A. C., Hickman, M., Araya, R., Teesson, M., Newton, N. C., ... Heron, J. (2016). Drinking to Cope: a latent class analysis of coping motives for alcohol use in a large cohort of adolescents. Prevention Science: The Official Journal of the Society for Prevention Research. http://doi.org/10.1007/s11121-016-0652-5

Stern, D. (1985). The interpersonal world of the infant: a view from psychoanalysis and developmental psychology. New York: Basic Books.

Surman, C. B. H., Biederman, J., Spencer, T., Miller, C. a, McDermott, K. M., \& Faraone, S. V. (2013). Understanding deficient emotional selfregulation in adults with attention deficit hyperactivity disorder: a controlled study. Attention Deficit and Hyperactivity Disorders, 5, 27381. http://doi.org/10.1007/s12402-012-0100-8 
Svartberg, M., Stiles, T. C., \& Seltzer, M. H. (2004). Randomized, controlled trial of the effectiveness of short-term dynamic psychotherapy and cognitive therapy for cluster $\mathrm{C}$ personality disorders. The American Journal of Psychiatry, 161, 810-817. http://doi.org/http://dx.doi.org/10.1176/appi.ajp.161.5.810

Sweatt, J. D. (2013). The emerging field of neuroepigenetics. Neuron, 80(3), 624-632. http://doi.org/10.1016/j.neuron.2013.10.023

Thompson, R. A. (1994). Emotion Regulation: A theme in Search of Definition. Monographs of the Society for Research in Child Development, 59, 25-52.

Thompson, R. A. (2011). Emotion and emotion regulation: Two sides of the developing coin. Emotion Review, 3, 53-61. http://doi.org/10.1177/1754073910380969

Tomkins, S. S. (1981). The quest for primary motives: biography and autobiography of an idea. Journal of Personality and Social Psychology, 41(2), 306-329. Retrieved from http://ovidsp.tx.ovid.com.proxy.kib.ki.se

Tomkins, S. S. (2008). Affect Imagery Consciousness : The Complete Edition. New York: Springer Publishing. (Original work published 1962-63).

Tracey, T. J., \& Kokotovic, A. M. (1989). Factor structure of the Working Alliance Inventory. Psychological Assessment, 1, 207-210. http://doi.org/10.1037//1040-3590.1.3.207

Tracy, J. L., \& Randles, D. (2011). Four models of basic emotions: A review of Ekman and Cordaro, Izard, Levenson, and Panksepp and Watt. Emotion Review, 3, 397-405. http://doi.org/10.1177/1754073911410747

Tull, M. T., Gratz, K. L., Salters, K., \& Roemer, L. (2004). The role of experiential avoidance in posttraumatic stress symptoms and symptoms of depression, anxiety, and somatization. The Journal of Nervous and Mental Disease, 192(11), 754-61. Retrieved from http://www.ncbi.nlm.nih.gov/pubmed/15505519

van Emmerik-van Oortmerssen, K., van de Glind, G., van den Brink, W., Smit, F., Crunelle, C. L., Swets, M., \& Schoevers, R. A. (2012). Prevalence of attention-deficit hyperactivity disorder in substance use disorder patients: a meta-analysis and meta-regression analysis. Drug and Alcohol Dependence, 122, 11-9. http://doi.org/10.1016/j.drugalcdep.2011.12.007

VanDerhei, S., Rojahn, J., Stuewig, J., \& McKnight, P. E. (2014). The Effect of shame-proneness, guilt-proneness, and internalizing tendencies on nonsuicidal self-injury. Suicide and Life-Threatening Behavior, 44, 317-330. http://doi.org/10.1111/sltb.12069 
Wampold, B., \& Imel, Z. (2013). The great psychotherapy debate : The evidence for what makes psychotherapy work (2nd ed.). Routledge.

Ward, M. F., Wender, P. H., \& Reimherr, F. W. (1993). The Wender Utah Rating Scale: an aid in the retrospective diagnosis of childhood attention deficit hyperactivity disorder. The American Journal of Psychiatry, 150(6), 885-90. http://doi.org/10.1176/ajp.150.6.885

Wennberg, P., Philips, B., \& de Jong, K. (2010). The swedish version of the outcome questionnaire (OQ-45): Reliability and factor structure in a substance abuse sample. Psychology and Psychotherapy: Theory, Research and Practice, 83, 325-329. http://doi.org/10.1348/147608309X478715

Wilens, T. E., \& Dodson, W . (2004). A clinical perspective of attentiondeficit/hyperactivity disorder into adulthood. The Journal of Clinical Psychiatry, 65(10), 1301-13. Retrieved from http://www.ncbi.nlm.nih.gov/pubmed/15491232

Wilens, T. E., Kwon, A., Tanguay, S., Chase, R., Moore, H., Faraone, S. V., \& Biederman, J. (2005). Characteristics of Adults with Attention Deficit Hyperactivity Disorder Plus Substance Use Disorder: The Role of Psychiatric Comorbidity. American Journal on Addictions, 14, 319327. http://doi.org/10.1080/10550490591003639

Windle, M., \& Scheidt, D. M. (2004). Alcoholic subtypes: are two sufficient? Addiction, 99, 1508-19. http://doi.org/10.1111/j.13600443.2004.00878.x

Winston, A., Laikin, M., Pollack, J., Samstag, W., McCullough, L., \& Muran, J. (1994). Short-term psychotherapy of personality disorders. American Journal of Psychiatry, 151, 190-194. Retrieved from http://dx.doi.org/10.1176/ajp.151.2.190

Wise, B. K., Cuffe, S. P., \& Fischer, T. (2001). Dual diagnosis and successful participation of adolescents in substance abuse treatment. Journal of Substance Abuse Treatment, 21(3), 161-5. Retrieved from http://www.ncbi.nlm.nih.gov/pubmed/11728790

Young, S., \& Sedgwick, O. (2015). Attention deficit hyperactivity disorder and substance misuse: an evaluation of causal hypotheses and treatment considerations. Expert Review of Neurotherapeutics, 15, 1005-1014. http://doi.org/10.1586/14737175.2015.1059756

Young, S., Sedgwick, O., Fridman, M., Gudjonsson, G., Hodgkins, P., Lantigua, M., \& González, R. (2015). Co-morbid psychiatric disorders among incarcerated ADHD populations: a meta-analysis. Psychological Medicine, 45, 2499-2510. http://doi.org/10.1017/S0033291715000598

Öjehagen, A., Berglund, M., Appel, C. P., Andersson, K., Nilsson, B., Skjaerris, A., \& Wedlin-Toftenow, A. M. (1992). A randomized study of long-term out-patient treatment in alcoholics. Psychiatric treatment 
versus multimodal behavioural therapy, during 1 versus 2 years of treatment. Alcohol and Acoholism, 27, 649-658. Retrieved from http://alcalc.oxfordjournals.org.proxy.kib.ki.se 


\section{Papers}

The papers associated with this thesis have been removed for copyright reasons. For more details about these see:

http:// urn.kb.se/ resolve?urn=urn:nbn:se:liu:diva-143192 


\section{LINKÖPING STUDIES IN BEHAVIOURAL SCIENCE}

166. SANDBERG, FREDRIK. Recognition of Prior Learning in Health Care. From a Caring Ideology and Power, to Communicative Action and Recognition. 2012. ISBN: 978-91-7519-814-9

167. FÄGERSTAM, EMILIA. Space and Place. Perspectives on Outdoor Teaching and Learning. 2012. ISBN: 978-91-7519-813-2

168. FALKENSTRÖM, FREDRIK. The Capacity for Self-Observation in Psychotherapy. 2012. ISBN: 978-91-7519-797-5

169. BENNICH, MARIA. Kompetens och kompetensutveckling i omsorgsarbete. Synen på kompetens och lärande i äldreomsorgen - i spänningsfältet mellan samhälleliga förutsättningar och organisatoriska villkor. 2012. ISBN: 97891-7519-777-7

170. RUSANGANWA, JOSEPH. Enhancing Physics Learning through Instruction, Technical Vocabulary and ICT. A Case of Higher Education in Rwanda. 2012. ISBN: 978-91-7519-739-5

171. MBABAZI, PENELOPE. Quality in Learning in Rwandan Higher Education: Different Stakeholders' Perceptions of Students' Learning and Employability. 2013. ISBN: 978-91-7519-682-4

172. BYSTRÖM, ERICA. Ett lärorikt arbete? Möjligheter och hinder för undersköterskor att lära och utvecklas i sjukvårdsarbetet. 2013. ISBN: 978-917519-679-4

173. KAGWESAGE, ANNE MARIE. Coping with Learning through a Foreign Language in Higher Education in Rwanda. 2013. ISBN: 978-91-7519-640-4

174. MUTWARASIBO, FAUSTIN. Understanding Group-based Learning in an Academic Context: Rwandan Students' Reflections on Collaborative Writing and Peer Assessment. 2013. ISBN: 978-91-7519-633-6

175. MÅRDH, SELINA. Cognitive erosion and its implications in Alzheimer's disease. 2013. ISBN: 978-91-7519-612-1

176. HARLIN, EVA-MARIE. Lärares reflektion och professionella utveckling Med video som verktyg. 2013. ISBN: 978-91-7519-611-4

177. ÖSTERGREN, RICKARD. Mathematical Learning Disability. Cognitive Conditions, Development and Predictions. 2013. ISBN: 978-91-7519-565-0 
178. ENGVALL, MARGARETA. Handlingar i matematikklassrumet. En studie av undervisningsverksamheter på lågstadiet då räknemetoder för addition och subtraktion är i fokus. 2013. ISBN: 978-91-7519-493-6

179. JOHANSSON, ROBERT. Treating depression and its comorbidity. From individualized Internet-delivered cognitive behavior therapy to affectfocused psychodynamic psychotherapy. 2013. ISBN: 978-91-7519-467-7

180. BERGMAN NORDGREN, LISE. Individually tailored internet-based cognitive behavioural therapy for anxiety disorders. 2013. ISBN: 978-917519-459-2

181. FREJD, PETER. Modes of Mathematical Modelling. An Analysis of how modelling is used and interpreted in and out of school settings. 2014. ISBN: 978-91-7519-414-1

182. AMAN, ROBERT. Impossible Interculturality? Education and the Colonial Difference in a Multicultural World. 2014. ISBN: 978-91-7519-348-9

183. NYLANDER, ERIK. Skolning i jazz. Värde, selektion och studiekarriär vid folkhögskolornas musiklinjer. 2014. ISBN: 978-91-7519-347-2

184. GRADIN FRANZÈN, ANNA. Disciplining freedom: Treatment dilemmas and subjectivity at a detention home for young men. 2014. ISBN: 978-917519-344-1

185. ENGSTRÖM, ANNIKA. Lärande samspel för effektivitet. En studie av arbetsgrupper i ett mindre industriföretag. 2014. ISBN:978-91-7519-345-8

186. ELWÉR, ÅSA. Early Predictors of Reading Comprehension Difficulties. 2014. ISBN: 978-91-7519-281-9

187. LARSON, NICLAS. Matematikämnet och stadiebytet mellan grundskolan och gymnasieskolan. En enkät- och klassrumsstudie. 2014. ISBN: 978-917519-196-6

188. LY, HOA. Use of a Smartphone Application in the Treatment of Depression - The New Wave of Digital Tools for Psychological Treatment. 2015. ISBN: 978-91-7519-136-2

189. HANSSON, PER-OLOF. New ways of learning. Participatory action research and Kenyan runners' appropriation of smartphones to improve their daily lives and participation in m-learning. 2015. ISBN: 978-91-7519-124-9

190. BOLLDÈN, KARIN. Online teaching practices. Sociomaterial matters in higher education settings. 2015. ISBN: 978-91-7519-123-2 
191. MALMQUIST, ANNA. Pride and Prejudice. Lesbian families in contemporary Sweden. 2015. ISBN: 978-91-7519-087-7

192. AVBY, GUNILLA. Evidence in Practice. On Knowledge Use and Learning in Social Work. 2015. ISBN: 978-91-74519-088-4

193. FORSBERG, CAMILLA. Students' Perspectives on Bullying. 2016. ISBN: 978-91-7685-874-5

194. MUHRMAN, KAROLINA. Inget klöver utan matematik. En studie av matematik i yrkesutbildning och yrkesliv. 2016. ISBN: 978-91-7685-851-6

195. SKAGERLUND, KENNY. Magnitude Processing in Developmental Dyscalculia. A Heterogeneous learning disability with different cognitive profiles. 2016. ISBN: 978-91-7685-831-8

196. EKEBLAD, ANNIKA. A Randomized Trial of Interpersonal Psychotherapy and Cognitive Behavioral Therapy for Major Depressive Disorder Predictors of process and outcome. 2016. ISBN: 978-91-7685-803-5

197. MÅNSSON, KRISTOFFER N.T. Restructuring the Socially Anxious Brain. Using magnetic resonance imaging to advance our understanding of effective cognitive behaviour therapy for social anxiety disorder. 2016. ISBN: 978-91-7685-688-8

198. SILFVERNAGEL, KRISTIN. Individually tailored internet-based cognitive behavioural therapy for adolescents, young adults and older adults with anxiety. 2017. ISBN: 978-91-7685-566-9

199. ELOFSSON, JESSICA. Children's early mathematics learning and development. Number game interventions and number line estimations. 2017. ISBN: 978-91-7685-517-1

200. ÅHLFELDT, EMANUEL. Hållbart utvecklingsarbete i vård och omsorg. Ett institutionellt perspektiv på projekt i en professionell och byråkratisk kontext. 2017. ISBN: 978-91-7685-445-7

201. VERNMARK, KRISTOFER. Working alliance and different treatment formats when delivering internet-based treatment for depression. 2017. ISBN: 978-91-7685-436-5 